\title{
An Evaluation of State Employees' Preferences for Worksite- based Physical Activity, Nutrition, and Stress Management Programs
}

\author{
Peter Kadushin \\ West Virginia University
}

Follow this and additional works at: https://researchrepository.wvu.edu/etd

\section{Recommended Citation}

Kadushin, Peter, "An Evaluation of State Employees' Preferences for Worksite-based Physical Activity, Nutrition, and Stress Management Programs" (2014). Graduate Theses, Dissertations, and Problem Reports. 196.

https://researchrepository.wvu.edu/etd/196

This Dissertation is protected by copyright and/or related rights. It has been brought to you by the The Research Repository @ WVU with permission from the rights-holder(s). You are free to use this Dissertation in any way that is permitted by the copyright and related rights legislation that applies to your use. For other uses you must obtain permission from the rights-holder(s) directly, unless additional rights are indicated by a Creative Commons license in the record and/ or on the work itself. This Dissertation has been accepted for inclusion in WVU Graduate Theses, Dissertations, and Problem Reports collection by an authorized administrator of The Research Repository @ WVU.

For more information, please contact researchrepository@mail.wvu.edu. 
An Evaluation of State Employees' Preferences for Worksite-based Physical Activity, Nutrition, and Stress Management Programs

Peter Kadushin, M.S.

Dissertation submitted

to the College of Physical Activities and Sport Sciences

at West Virginia University

in partial fulfillment of the requirements for the degree of

Doctor of Philosophy in

Kinesiology

Sam Zizzi, Ed.D., Chair

Bill Reger-Nash, Ed.D.

Christiaan Abildso, Ph.D.

Damien Clement, Ph.D., ATC

Nidia I. Henderson, M.S.

Department of Sport Sciences

Morgantown, West Virginia

2014

Keywords: Worksite Wellness, Physical Activity, Nutrition, Stress Management Copyright 2014 Peter Kadushin 


\begin{abstract}
An Evaluation of State Employees' Preferences for Worksite-based Physical Activity, Nutrition, and Stress Management Programs

Peter Kadushin, M.S.

Worksite wellness programs (WWPs) have evolved over the last several decades as a way to positively impact employees' health, and to manage rising healthcare costs. Despite the impact that WWPs can have both clinically and financially, participation rates in many programs remain low. Some research has reported success in increasing participation and engagement through tailoring programs to fit employee preferences. The purpose of this study was to investigate the wellness programming preferences of state employees in West Virginia. A secondary purpose was to identify how these preferences differ by health risk, worksite wellness participation, age, and gender. Respondents $(N=18,791)$ completed a survey that was developed in collaboration with the Public Employees Insurance Agency of West Virginia, with respondents reporting strong interest in nutrition $(77.6 \%)$, physical activity $(81.0 \%)$, and stress management programming $(61.1 \%)$, and with a 'personalized webpage' being the most preferred contact method. Interest in wellness programming was higher for females, previous participants, and those who were classified as 'high risk.' Focus groups $(N=4)$ were also conducted at worksites around the state, with employees $(n=24)$ reporting a lack of knowledge surrounding what programming was offered, and how to get involved. Participants also suggested that future programming should include education tailored to how they could become healthier. Overall the results highlight a lack of familiarity with wellness programs, which was a major barrier to participation. However, interest in wellness programming was high, which suggests that if employees are made aware of what is available, these programs might be taken advantage of.
\end{abstract}




\section{Acknowledgments}

Before reading any further, you should know that this document wouldn't exist if it weren't for the guidance I received from Dr. Sam Zizzi. Beyond the hard work you put into helping me reboot my dissertation several times, the countless drafts you were forced to read, and your enviable ability to see the big picture while hanging out in the dirt, you also provided support, encouragement, and respect I wasn't always sure I had earned. Beyond your help in the classroom, I will always be grateful for your wisdom; if you haven't found the answers, you certainly have lived the questions, and that's been a great model for me to follow. Thank you.

I would like to thank Nidia Henderson and the Public Employee's Insurance Agency for the opportunity to take on such an amazing project. Without the agency, there would be no project, but without Nidia, there would be no wellness programming to evaluate. Without your tireless work in this state, too many people would have gone without the opportunity to make their lives happier and healthier.

I'm grateful for Dr. Bill Reger-Nash's help in shaping my proposal, as well as being so generous with his wealth of knowledge surrounding wellness programming. You have such genuine positive energy, and if I can make half the positive impact you've made throughout your lifetime, I'll consider my personal and professional lives a success!

Many thanks to Dr. Christiaan Abildso. Your mind works in mysterious ways, and I can only hope that I picked up some of what you were putting down in the short time our paths crossed. Your feedback throughout the project was spot on, and you have continually forced me to think outside of the box whenever I approach a problem; a lesson I hope I won't soon forget.

I'd also like to extend a thank you to Dr. Damien Clement, my Master's Thesis chair. My journey into the professional world of Sport and Exercise Psychology began with your help, and it's only fitting that we see this through to the end. Thank you for being along for the entire journey, and for your patience while I was still getting out of the starting gate.

A big shout out to Chelsea "Dubz" Wooding and Megan "Chris Andersen" Byrd for their help in making this project actually happen. You guys rock, and one day, I may even repay your kindness...

I would also like to thank all the SPAFers that I've known over the last five years in Morgantown. A doctoral program can be a lonely place sometimes, and without your generosity, support, feedback, and the overwhelming number of shenanigans, I know that I wouldn't have made it.

Finally, I'd like to thank my incredible family. Moms, Pop, and Hank, you are my people, and I love you with all my heart. Thank you for everything you've given me. 


\section{Table of Contents}

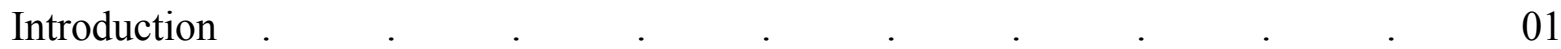

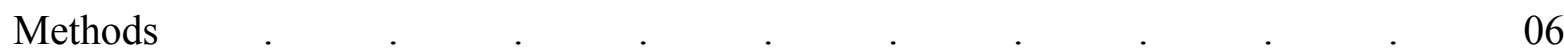

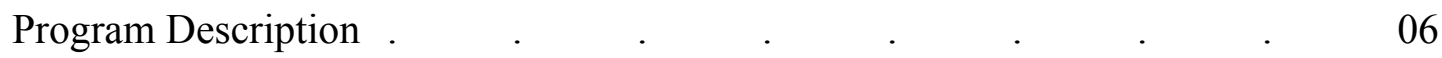

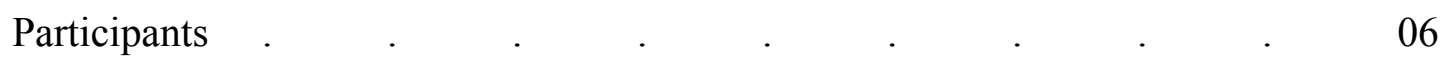

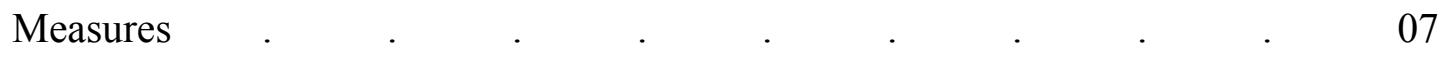

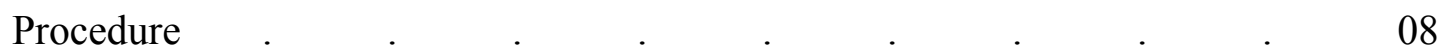

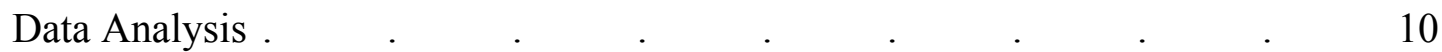

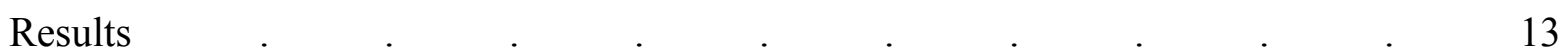

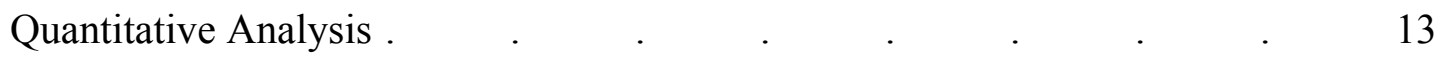

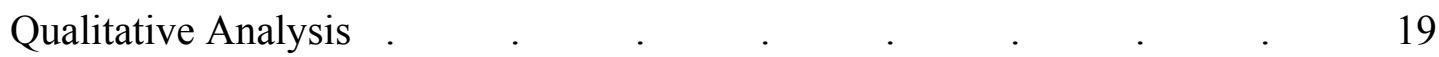

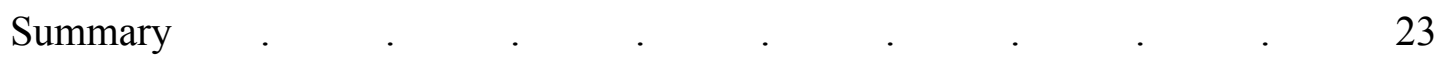

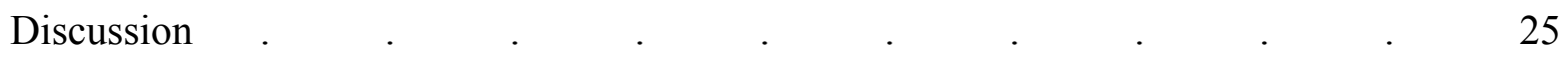

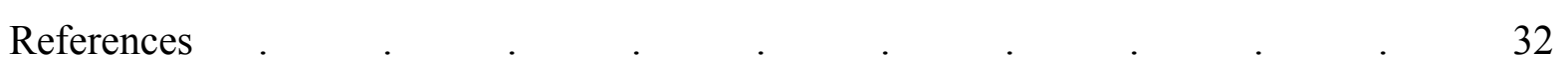

Appendix A - PEIA Wellness Survey $\quad . \quad$. $\quad . \quad$. $\quad . \quad$ see attached

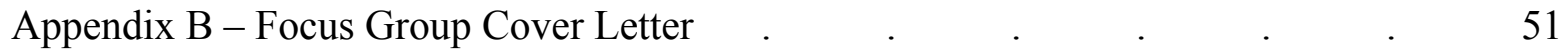

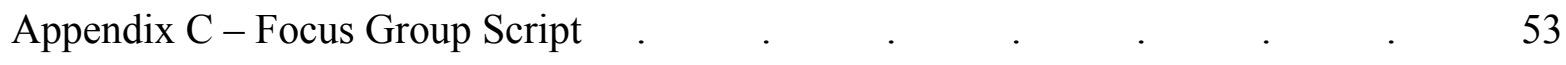

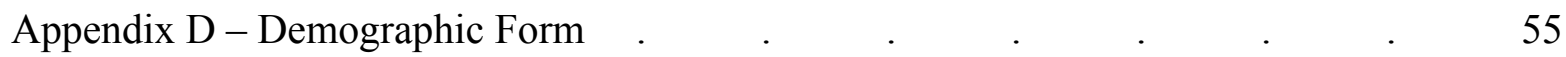

Appendix E - CDC Environmental Evaluation _ . $\quad . \quad$. $\quad . \quad$ see attached

Appendix F - Percentage of Respondents by County $\quad . \quad$. $\quad . \quad$. $\quad 58$

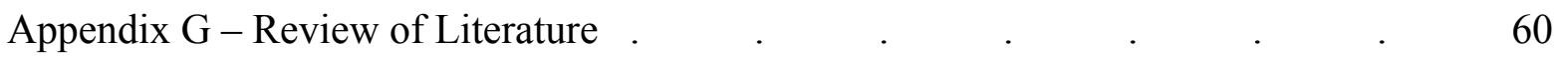




\section{List of Tables}

Table 1 - A Comparison of Wellness Survey Responses with General

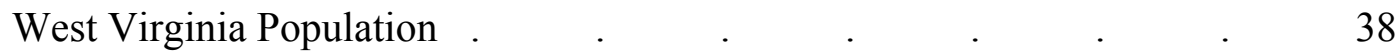

Table 2 - Income Stratification for Survey Respondents and West Virginia Residents 39

Table 3 - Preferences for Nutrition, Physical Activity, and Stress Management Programs 40

Table 4 - Delivery Preferences of Respondents $\quad$. $\quad$. $\quad$. $\quad$. $\quad$. $\quad 41$

Table 5 - Respondents' Preferred Incentives $\quad . \quad$. $\quad . \quad$. $\quad$. $\quad 42$

Table 6 - Worksite Availability from the Wellness Survey . . . . . . 43

Table 7 - CDC Environmental Evaluation - Nutrition Features $\quad$. . . . . 44

Table 8 - CDC Environmental Evaluation - Physical Activity Features 45

Table 9 - Breakdown of Respondents based on Risk and Participation Profile 46

Table 10 - Effect Sizes of the Fixed Factors and Covariate on Delivery Method

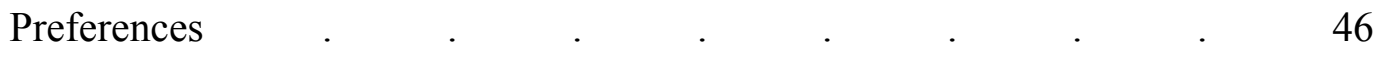

Table 11 - Adjusted Standardized Residuals for General Wellness Program Preferences 47

Table 12 - Adjusted Standardized Residuals for External Incentives _ 48

Table 13 - Adjusted Standardized Residuals for Intrinsic Incentives $\quad$ 49 


\section{Introduction}

The United States has struggled over the last several decades with the rise of unhealthy lifestyle behaviors, such as poor nutrition and physical inactivity (Mattke et al., 2013). The consequence of these behaviors has been an increase in the prevalence of chronic conditions such as cardiovascular disease (CVD), diabetes, and obesity, with lifestyle behaviors accounting for more than 2 million deaths per year (Mokdad, Marks, Stroup, \& Gerberding, 2004). Some estimate that CVD alone is responsible for about 30\% of all deaths each year (Pappachan, 2011). Unhealthy behaviors and their associated chronic conditions have also been linked to the rise in healthcare expenses that currently afflicts the United States. An estimated $\$ 613$ billion is spent on CVD, diabetes, and hypertension in 2003 , and with costs projected to increase through the next decade (Bodenheimer, Chen, \& Bennett, 2009). Looking for ways to reverse these trends, employers and interventionists have used worksite wellness programming to help individuals improve their health and curb increasing insurance expenses. With most adults spending a significant portion of their waking hours at work, the worksite provides a promising platform for wellness programming (Conn, Hafdahl, Cooper, Brown, \& Lusk, 2009). Worksites also provide access to preexisting social networks that allow for connecting people and resources in a way that might not be possible in other settings (Hutchinson \& Wilson, 2011).

Worksite wellness programs (WWPs) incorporate a variety of methods to promote awareness of, and changes to, employee health. These methods include health screenings and health risk assessments (HRAs) to help identify employees who are at risk and to raise their awareness of the need to change. Additional efforts include programming that aims to address the various health risks that impact chronic disease and insurance costs. The target behaviors of WWPs vary greatly, ranging from simple behaviors (e.g., drinking water) to more complex 
lifestyle change (e.g., learning to manage stress, establishing regular exercise habits). There is also a split across programs, with some WWPs focusing on disease management (e.g., controlling the adverse health effects of diabetes) and others providing health promotion strategies (e.g., how to become more physically active to lower blood pressure and cholesterol). In a 2012 survey of employers $(n=3,000)$ with WWPs, $71 \%$ offered health promotion-related "lifestyle management" programs, with nutrition (79\%), fitness (72\%), and stress management programs (52\%) being some of the most frequently offered interventions (Mattke et al., 2013). With the rise in prevalence of WWPs, the impact of wellness programming on clinical and economic outcomes has received additional attention from researchers.

Several reviews have identified a relationship between the participation in WWPs and positive health outcomes for employees and economic outcomes for employers. Based on several meta-analyses, reported effect sizes vary greatly depending on target behavior and methodology, however moderate effects have been reported for fitness interventions $(d=0.47-$ 0.57; Conn et al., 2009), which compares favorably to the small effects reported for lifestyle interventions as a whole (pooled generic ES = 0.24; Rongen, Robroek, van Lenthe, \& Burdorf, 2013). Similarly, exact return-on-investment calculations vary from study to study, however several reviews have put the estimate between roughly $\$ 3$ to $\$ 6$ for every dollar spent, suggesting that investing in employee wellness is still money well spent (Baicker, Cutler, \& Song, 2010, Chapman, 2005). These findings are encouraging, but most evaluations are not able to parcel out the key components responsible for these positive outcomes.

An important barrier preventing WWPs from making a more profound impact is a lack of employee participation and engagement in wellness programming. One review marked the median participation rate of employees at 34\% for WWPs, which suggests that despite the best 
efforts of interventionists and evaluators, wellness programming still does a poor job of getting employees to participate (Robroek, van Lenthe, van Empelen, \& Burdorf, 2009). Without participating, employees will not build the knowledge, skills, or abilities that facilitate health behavior change. Beyond simply participating, there is also evidence to suggest that employees who are more engaged in wellness programming are more likely to accrue the positive benefits of participation. In one study, participants who completed HRAs yearly were more likely to report fewer health risks and healthcare costs than those who completed them less frequently (Serxner, Gold, Grossmeier, \& Anderson, 2003). One recent program evaluation showed increased engagement (i.e., live coaching or virtual programming paired with an HRA, compared to simply completing an HRA) was also related to improved clinical outcomes (Loeppke, Edington, Bender, \& Reynolds, 2013). The relationship between increased engagement and increased effect has also been replicated for web-based programming, with one study finding that participants who logged on to the intervention site more frequently were more likely to lose weight than those with lower usage (Morgan et al., 2011).

A number of studies have identified a bias in WWPs, with people who are already healthy taking advantage of these programs more often than those with more health risk factors (Lewis, Huebner, \& Yarborough, 1996). In one review, the authors also found that high-income employees, as well as employees with low healthcare costs, were more likely to participate in wellness programming (Merril \& Hull, 2013). Some wellness programs may encourage this imbalance incidentally, with structural barriers such as programming during non-work hours that discourages participation for lower income employees, who may need to work overtime, second jobs, or who cannot afford additional childcare (Sorensen, Linnan, \& Hunt, 2004). These employees are more likely to have increased health risks and may also be in a position where 
they cannot take time off from work to participate in wellness programming, further limiting the opportunities to improve their health (Ross \& Wu, 1995). In addition, some wellness programs may go a step further and punish unhealthy employees by asking them to shoulder additional insurance costs, often by not allowing them to qualify for reduced premiums (Horwitz, Kelly, \& DiNardo, 2013). Although new provisions have been written into the Affordable Care Act that are aimed at ensuring companies provide more inclusive wellness programming, there remains an imbalance between participation rates for at-risk employees and their healthier coworkers (Moran, 2013). Without stepping back to examine the ways that WWPs engage employees and attempt to influence health behaviors, it is unlikely that this trend will change.

Many programs look to engage employees through a shift in decisional balance, by either making unhealthy choices seem "bad," or by making healthy options look more attractive. Some interventions influence health decisions by making the immediate option less appealing (e.g., using fear of CVD to reduce fat consumption), while others attempt to increase the value of healthy decisions (e.g., providing incentives for going to the gym; Norman, Boer, \& Seydel, 2005). Research suggests that both incentives and fear are effective at encouraging people to adopt behaviors, but may not be equally effective at sustaining behavior (Loveman et al., 2011). In contrast, by providing meaningful choices of engagement, individuals may feel more autonomous and intrinsically motivated to continue these new behaviors (Ryan, Patrick, Deci, \& Williams, 2008).

Some programs have reported success by providing tailored choices for wellness programming that allow employees to experience a sense of control over their health behaviors (Wantland, Portillo, Holzemer, Slaughter, \& McGhee, 2004). Programs that focus on developing personal meaning and employee competence have also reported larger clinical effects than 
programs using other approaches (Hutchinson \& Wilson, 2011). Similarly, programs that addressed health behavior change from a systems approach (i.e., affecting change through individual, environmental, and structural change; Sorensen et al., 1999) have also reported increased success. However, many of these programs are implemented with small samples and are usually resource-intensive (e.g., in-person meetings, building new fitness facilities), making them ineffective models when trying to scale programs to fit larger populations.

Many employers may hesitate to implement programs that are resource intensive, despite the fact that they may have a greater impact on employees' health. To address the issue of creating programs that can increase engagement while limiting the resources necessary to positively impact employees, many WWPs have begun using technology-based interventions. There is growing evidence that when structured correctly, web-based programming can be as effective as in-person meetings in positively influencing health behaviors (Wolever et al., 2012). Not only does the use of technology-based interventions have the potential to reduce barriers to participation (e.g., not having the time to participate during work hours), but it may also increase engagement by providing people with the opportunity to engage their health behaviors in their own way (Eisen, Allen, Bollash, \& Pescatello, 2008).

There is evidence that when employees are able to provide input in the development of the program, and they are given appealing choices, they experience a sense of control over their health behaviors (LeCheminant \& Merrill, 2012; Wantland et al., 2004). With this in mind, it is valuable for employers to identify what types of programming employees are interested in, as well as their preferred way of interacting with wellness programs. Therefore, the purpose of the current study is to explore the wellness programming preferences of a large sample of state employees in West Virginia. A secondary purpose for this study is to identify how these 
preferences differ across a number of variables, including health risks, WWP participation history, age, and gender.

\section{Methodology}

\section{Program Description}

The Public Employees Insurance Agency (PEIA) of West Virginia created the Pathways to Wellness program in the early 1990s in an effort to provide a variety of wellness programs across the state. These programs include health screenings and lifestyle management interventions (e.g., tobacco cessation, diabetes, heart disease, and weight management programs) that are offered across the state. The Pathways to Wellness program currently offers incentives, in the form reduced premium payments, to employees based on their engagement in wellness programming and for being tobacco free. The primary objectives of the Pathways to Wellness program are to reduce health risk factors, provide chronic disease management education, and reduce the imbalance in care for chronic conditions for public employees across West Virginia ("Pathways to Wellness", n.d.). Additionally, PEIA has tried to emphasize the development of programming that ensures ease of access to and statewide availability of their wellness offerings.

\section{Measures}

Wellness Survey. The PEIA Wellness Survey (see Appendix A) was a 38-item instrument developed using input from multiple stakeholders working with the current wellness program. The survey included sections regarding previous experiences with wellness programming ( 3 items), current health behaviors ( 7 items), preferences related to wellness programming (10 items), preferred delivery methods of wellness program information and technology use (6 items), and demographic information (8 items). The questions related to current health behaviors and programming preference were divided into specific questions 
relating to nutrition, physical activity, and stress management. The technology questions asked participants to describe their access to different devices or media (e.g., smart phone) and their current use of technology related to their health behaviors (e.g., using an app to track their meals or fitness activities). After initial development, the survey was piloted with PEIA members at one worksite in order to receive feedback on the design, readability, and content of the survey, and feedback was used to revise the survey. The pilot participants reported completing the survey in a range of 10-15 minutes.

Several items were used to provide an understanding of how respondents' preferences differed across demographic variables. Item 6 of the survey asked participants to rate their preferences for wellness information delivery methods (e.g., a personalized webpage with resources related to your health, taking with someone in person) using a 4-point likert scale from 1 (not at all interested) to 4 (very interested). Items 7, 15, 20, 26, and 30 were categorical variables that were also used in more detailed analyses. Items 7 (external incentives) and 30 (intrinsic incentives) asked respondents to select which incentives would encourage them to begin or continue participating in a wellness program. Items 15 (nutrition), 20 (physical activity), and 26 (stress management) asked respondents whether or not they would be interested in programming, allowing respondents to select 'yes' or 'no.'

Focus Group Script. A script that included six questions and instructions (see Appendix B) was used to guide the focus groups. The questions for the script were developed for the purpose of understanding members' experiences and preferences related to wellness programs, and drew from a combination of the phenomenological approach to qualitative inquiry (Creswell, 2013) and the structure of the PEIA Wellness Survey. More specifically, the focus group questions were open-ended, providing the participants an opportunity to generate meaningful 
textural descriptions of their experiences and preferences related to WWPs, but were in parallel with the specific sections addressed in the PEIA Wellness survey. This contrasts with the traditional phenomenological approach, which would only have one or two open-ended questions, and allow the themes to emerge solely from the focus group participants.

CDC Environmental Evaluation. To add to the structural description of the focus group data, the worksite wellness coordinators were asked to complete parts of the worksite evaluation created by the Community Health Assessment and Group Evaluation Action Guide (see Appendix E; Centers for Disease Control and Prevention, 2011). The evaluation was developed to assess the built environment and worksite culture related to health behaviors, including physical activity, nutrition, chronic disease management, and the leadership of WWPs.

\section{Participants}

Participants were collected from two different populations for the current study. All participants were recruited from a population of members who were covered under a healthcare plan offered by PEIA. For the PEIA Wellness Survey, responses were collected from a sample that consisted of all PEIA policyholders who had provided an e-mail address to the insurance agency $(n=46,780)$, which is roughly $67 \%$ of all policyholders $(N=70,021)$. In order to recruit focus group participants, worksite wellness coordinators (WWCs) who agreed to facilitate a focus group at their worksite were asked to gauge the interest of their employees. Coordinators were prompted to try and recruit participants who had varying demographic backgrounds (e.g., participants and non-participants, varying ages) in an effort to collect a broader range of experiences in each focus group. 


\section{Procedure}

Wellness Survey. Prior to beginning the study, approval was given by the insurance agency to proceed with an evaluation of its members. An IRB addendum for the study was added to an ongoing evaluation of the PEIA wellness programs. Participants for the survey were contacted through Survey Monkey, and had the opportunity to complete the survey online, request a paper copy of the survey, or decline participation. Using the e-mail list, potential respondents received three follow-up e-mails, seven days apart, over the course of four weeks in an effort in an effort to reach a 30\% response rate, which is typical in web surveys (Cook, Heath, \& Thompson, 2000; Dillman, 2000).

Focus Groups. Most state worksites have a WWC, who were seen as the gatekeepers when recruiting for worksite-based focus groups. To recruit these WWCs, respondents to the Wellness Survey were asked to: a) identify if they were a WWC for their worksite; and b) provide their e-mail address if they were interested in hosting a focus group at their worksite. A list of potential worksites was compiled $(n=62)$, and the health promotions director of the insurance agency helped to identify which worksites to contact. Of the coordinators contacted, four agreed to host a focus group, and were asked to recruit 5-10 employee volunteers to participate.

Coordinators were asked to check with the director of the worksite to acquire approval to use the facility and the time of the employees, and reserved a space at the worksite at which the focus groups took place. The WWCs were given the freedom to recruit participants how they saw fit, but were encouraged to send a reminder to participants prior to the date of the focus groups. Focus groups took place during employees' lunch hour, and the participants were provided with lunch, using funding from an internal grant from the University. 
Focus group participants completed a brief demographic form (see Appendix D) that included their age group, gender, previous WWP experience, height and weight. The focus groups were limited to one hour since they will occur during employees' workday. The focus groups were facilitated by the primary researcher, who allowed participants to answer the prompts and encouraged group interaction. A second researcher was also present to assist with audiotaping and recording group processing information (e.g., who was speaking, non-verbal communication, etc.).

CDC Environmental Evaluation. The worksite coordinators also completed the Centers for Disease Control and Prevention (CDC) environmental evaluation to help assess their worksite's environment and culture. To limit the time and resource burden of completing the evaluation, coordinators were only asked to complete the "environment response" column for the physical activity and nutrition sections. Responses to each question (e.g., "Does leadership evaluate company-sponsored health promotion programs?) range from 1 (elements not in place) to 5 (all elements in place), and a score is generated based on the percentage of possible points earned across each section. The responses to the evaluation provide environmental context for each of the worksites where focus groups were conducted.

\section{Data Analysis}

The study used three different data sources in an effort to characterize the preferences of state employees related to worksite wellness programming. The primary frame of reference for the data analysis was the results of the PEIA Wellness Survey, which provides the lens through which the focus group and worksite evaluation data were interpreted. By collecting data related to employee preferences in a number of contexts, the study attempted to add additional 
dimensions to the understanding of how employees prefer to engage worksite wellness programming.

Quantitative Analysis. Consistent with the first purpose of the study, descriptive statistics were compiled to provide a summary of participants' responses to the survey data. To address the second purpose of the study, a health risk score was calculated for each respondent. Self-reported hypertension, high cholesterol, tobacco use, and obesity were each weighted as "1", while self-reported diabetes and cardiovascular disease were weighted as " 2 ". Respondents with a score of zero were classified as 'No Risk', respondents with a score of one were categorized as 'Moderate Risk' and anyone with a score of two or higher was classified as 'High Risk'. Previous participation was defined using items 4 and 5 from the survey, with "nonparticipators" being defined as respondents who have never engaged in health screenings or other worksite wellness programming offered by PEIA. Six risk profiles were developed: NonParticipant/No Risk; Non-Participant/Moderate Risk; Non-Participant/High Risk; Participant/No Risk; Participant/Moderate Risk; Participant/High Risk. Prior to between-group analyses, a twoway ANOVA, with health status and participation as independent factors, was run to compare mean age across the six profiles. A $2 \times 2 \times 3$ chi-square test was run to assess differences in gender across the health status and participation variables. Both tests were significant to $p<.001$, and age and gender were included in subsequent analyses.

In order to investigate the differences across the risk profiles for item 6 , a three-way ANCOVA (health status $\mathrm{x}$ participation $\mathrm{x}$ gender) was run, using age as a covariate, comparing the means for the six different delivery methods. For the dichotomous dependent variables (items 7, 15, 20, 26 and 30), chi-square tests were run to determine significant differences between the profiles. Since the gender analysis was significant, the six risk profiles were divided 
by gender (health risk x participation $\mathrm{x}$ gender). In order to gain a better understanding of how incentive and programming preferences differed across the profiles, adjusted standardized residuals were used. The adjusted standardized residual calculation takes into account the overall size of the sample, and creates a standardized score representing the difference between the expected count of a cell if the variables were independent, compared to the observed count found in the cell (Bearden, 2010). This value provided a way to compare the differences in preferences across profiles in a standardized way.

Qualitative Analysis. Prior to analysis, the primary researcher transcribed the focus group data. Consistent with the phenomenological approach to qualitative inquiry, the transcribed data were analyzed by both the primary researcher and a secondary assistant, looking for statements that provide understanding of participants' experiences and preferences related to WWPs. During the first round of analysis, the researchers identified recurring statements across each focus group. Prior to the second round of analysis, both researchers identified themes based on the structure of the quantitative analyses: a) previous experience with WWPs; b) current health behaviors; c) preferences related to WWP structure; d) preferences related to incentives; e) barriers to participating in WWPs; and f) preferences related to contact methods. While this procedure diverged from traditional phenomenological inquiry, it allowed for more meaningful application of the focus groups results to the survey outcomes. Reliability was $55 \%$ after reviewing the first transcript. To reach agreement, both researchers reviewed the transcripts together, resolving discrepancies until there was consensus for each code. During the final round of coding, the researchers also provided a second level of coding to help organize the types of responses within each of the six higher order themes (e.g., preferences - social support, preferences - tailoring, etc.). 


\section{Results}

The final number of survey respondents was 18,791 , which represents a $40 \%$ response rate. There were at least 27 responses from all 55 counties in West Virginia, and 36 counties had over 100 responses each (see Appendix F). Twenty-four participants took part in the three focus groups. Additional feedback was collected from thirteen participants at a fourth worksite, however due to logistical constraints, these responses were not in the focus group format outlined in the procedure section. All four of the WWCs involved in the project completed the CDC Environmental Evaluation.

\section{Quantitative Analysis}

The average respondent to the Wellness survey was 48.06 years old $(\mathrm{SD}=11.17)$, was female $(66.2 \%)$ and had a BMI of $29.36(\mathrm{SD}=7.50)$. On average, respondents described their health as 'good', with a mean of $3.36(\mathrm{SD}=0.84)$ on a 5-point likert scale from 1 (poor) to 5 (excellent). With regards to previous experience with PEIA wellness programming, 70.5\% $(n=$ $13,071)$ had previously participated in the 'Improve Your Score' program at least once, $12.3 \%(n$ $=2,309)$ had participated in the Weight Management Program, 5.8\% $(n=1,086)$ had been a part of the Face to Face Diabetes program, and $19.8 \%(n=3,715)$ reported having previously participated in some other wellness program offered at their worksite. Only a small portion of the respondents had participated in one of the Dean Ornish programs offered by PEIA $(n=158$, $0.8 \%)$

Overall, there were some notable differences when respondents were compared to West Virginia averages retrieved from the BRFSS and U.S. Census (see Table 1). Specifically, the study sample reported a higher number of high school (99.7\% vs. $83.4 \%)$ and college (64.2\% vs. $17.9 \%$ ) graduates when compared with West Virginia as a whole. A majority $(57.2 \%)$ of survey 
respondents were classified as making $\$ 50,000$ or more, compared to $28.1 \%$ of the West Virginia population. For respondents, $6.2 \%$ reported making less than $\$ 25,000$, while $38.3 \%$ of the population fell into that income category (see Table 2). These prevalence numbers present a survey sample that is not economically representative of West Virginia as a whole. The income category of respondents was also compared with previous participation in wellness programming. For respondents who reported making less than $\$ 50,000$ and who had previously participated in wellness programming, the adjusted standardized residual was -4.4 . Previous participants who reported an income between $\$ 50,000$ and $\$ 95,000$ had a residual of 3.6 , and for the $\$ 95,001$ to $\$ 140,000$, the residual score was 4.5 . Taken together, these scores suggest that there is a connection between income and participation, with lower income policyholders being less likely to have previously participated in programming.

The differences in income and education level would suggest that the survey sample would also report lower prevalence rates of health risks when compared to overall population rates, which generally held true. Respondents reported lower prevalence rates of certain health risks, including hypertension, high cholesterol, and diabetes. Despite these differences, it may be misleading to suggest that the current sample is "healthier" than the average West Virginian. With an average BMI of just under 30 , and with the majority of the survey sample not meeting physical activity and nutrition guidelines, it may be possible that the sample simply has not experienced the negative consequences associated with excess weight, unhealthy nutrition behaviors, and a sedentary lifestyle.

Familiarity and Preferences in Wellness Programming. A majority of respondents reported having previously participated in wellness programming offered by the agency, however respondents familiarity with PEIA's wellness programming was low, with a mean of 
$2.64(\mathrm{SD}=1.06)$ on a 5-point likert scale from 1 (not at all familiar) to 5 (very familiar). Overall interest in wellness programming was high, with $77.6 \%(n=14,024)$ of the sample responding positively to the prompt "Would you be interested in wellness options related to helping you eat better?", $81.0 \%(n=14,510)$ responding positively when asked about physical activity programs, and $61.1 \%(n=10,862)$ reporting interest in stress management programming. The general preferences, along with specific programs that respondents reported interest in are summarized in Table 3. The nutrition programs that received the most frequent endorsement from respondents were a fruit and vegetable discount program (51.5\%) and a personalized webpage with a food $\log$ (28.5\%). The most selected physical activity programs were 'a discount on gym memberships' $(50.5 \%)$, 'a pedometer to track your steps throughout the day' $(34.7 \%)$, and 'in person exercise classes offered at your worksite' (33.8\%). For stress management programming, 'in person stress management classes' (24.9\%) and 'relaxation audio files' $(24.1 \%)$ were the most selected.

Of the technologies assessed (smart phone use, text messaging, use of an app to track food and exercise, and e-mail) responses on the survey suggest that e-mail may be the most viable way to reach potential participants, with $85.4 \%$ of the sample reporting that they use email at least once a day. For the sample, $67.1 \%$ also reported owning a smart phone, and 68.6\% reported text messaging at least once a day, while only $18.8 \%$ of the sample reported using an app or website to track their food and exercise. Respondents were also asked to rate several wellness information delivery methods on a 4-point likert scale from 1 (not at all interested) to 4 (very interested), with the results presented in Table 4. The highest rated delivery method was 'a personalized webpage with resources related to your health', with e-mail being the second highest. A large number of respondents reported that they text message at least daily, but overall, this method was not rated highly as a way of communicating wellness information. The 
opposite held true for smart phone apps, with the sample identifying it as the $3^{\text {rd }}$ most preferred method of delivery, but with a low number of respondents using a smart phone app currently.

Incentives for Wellness Programming. Respondents were asked to select their preference from a list of external incentives, with $69.6 \%$ of respondents identifying a discount on insurance premiums as the reward that would most motivate them to participate in a wellness program. When queried about intrinsic incentives, $32.6 \%$ of respondents chose learning new skills related to being healthy as the experience that would encourage them most to start or continue participating in a program. As a whole, respondents were much more divided across the intrinsic incentives, with none of the options being clearly 'most preferred' across the sample (see Table 5 for a comprehensive review of incentives).

Worksite Features and Environmental Evaluation. Of the worksite features highlighted on the wellness survey, the most frequently identified was a safe place to walk, with $41.1 \%$ of the sample reporting that they had either an indoor or outdoor walking path. The second most identified worksite feature was safe, unflavored drinking water provided to employees at no cost, with $39.6 \%$ of state employees reporting they had access to water at their worksite. While $25.9 \%$ of the sample reported that connecting with coworkers would be an incentive for wellness programming, worksite-based support groups or clubs for both healthy eating and physical activity were the lowest rated worksite features on the survey $(3.9 \%$ and $3.6 \%$ respectively; see Table 6 for all worksite availability options).

At each of the worksites visited during data collection, the wellness coordinators agreed to complete portions of the CDC environmental evaluation. All four of the worksites were public, not-for-profit institutions, with two school/education worksites, one healthcare worksite, and one governmental worksite. Three of the worksites reported having between 20-99 
employees, while one site reported employing between 100-249 state employees. For responses to the nutrition-related questions across all four worksites, only four of the fifteen features were identified as having most or all of the elements in place for that specific feature (see Table 7). Those features were: a) safe, unflavored drinking water at no cost to the employee; b) refrigerator access; c) microwave access; and d) sink access.

For the physical activity portion of the evaluation, none of the features had a mean score above 3 , indicating that on average, few of the elements were in place to allow for physical activity interventions at the worksite (e.g., access to on-site fitness center, gymnasium, or physical activity classes; see Table 8).

Risk Profiles. The respondents of the wellness survey were categorized based on their health risks and their previous participation in PEIA sponsored wellness programming, creating six different risk profiles (see Table 9 for a breakdown of respondents by risk profile). All of the two-way ANCOVAs reported significant main effects for the risk profiles $(p<.001)$, and the main effects for gender on delivery preferences were significant for all of the methods assessed except for 'talking with someone in person' and 'talking with someone on the phone'. There were no significant interaction effects for the analyses run, but as a covariate, age was significant for all six of the delivery methods $(p<.001)$. Across the delivery methods, both gender and risk profile accounted for a small amount of variance in preference $(0.4-1.0 \%)$, whereas age had a significant main effect on respondents' preference for using smart phone apps, $F(1,15465)=$ 1181.23, $p<.001, \eta_{\mathrm{p}}{ }^{2}=.071$ (for a complete reporting of effect sizes see Table 10).

Chi-square analyses were run to assess the changes across risk profiles for a number of the categorical variables on the wellness survey. Looking first at the change in general preferences across the twelve risk profiles, there were some clear trends that emerged. Overall, 
residuals increased as respondents shifted from no risk towards high risk, and from nonparticipant to participant. The preferences for respondents classified as no risk were considerably lower than would be expected, and the discrepancy was exaggerated when looking specifically at non-participants who were classified as no risk (adjusted standardized residuals ranging from -2.6 to -10.6 ; see Table 11$)$. The exception to this trend was female participants with no risk factors, who had a residual of 4.2 for preferences towards physical activity. There was also a clear difference in preference when comparing males to females. Male respondents had residuals ranging from -10.6 (non-participant/no risk for nutrition programming) to 1.9 (participant/high risk for nutrition programming), while female respondents had residuals ranging from -5.5 (non-participant/no risk for nutrition programming) to 11.3 (participant/high risk for nutrition programming). The largest residuals were reported for high-risk female participants, which was consistent across nutrition, physical activity, and stress management programs (residuals of $11.3,7.8$, and 9.5 respectively). Overall this pattern of data suggests that participants and females are more likely to report interest in wellness programming.

The trends that emerged from the external incentive analysis were less clear than the preference analysis (see Table 12). For the item 'receiving a discount on your insurance premium', which received the majority of support from the overall sample, the risk profiles were divided, with male participants reporting large, positive residuals (1.9 to 6), while female nonparticipants had residual scores ranging from -3.3 to -6 . For both males and females, residuals decreased significantly when the shift was made from no risk to moderate/high risk, suggesting that a discount might be less appealing to those who reported risk factors. This trend is consistent across the twelve profiles. Interestingly, this trend reverses for the 'time off to participate in wellness programming' item. As risk increases, the negative residuals reported 
shift towards positive residuals, with the most pronounced difference being for male nonparticipants (a change from -3.3 to 2.5 ) and female participants (-4.6 to 3.6).

For intrinsic incentives, there appear to be a few clear differences that appear when looking at the residuals across the twelve risk profiles, particularly when comparing residuals across gender (see Table 13). Males were more likely to report that none of the intrinsic incentives were appealing to them, with the highest residual scores for no risk males (nonparticipants had a residual of 11.8 and participants a residual of 9.7). Females, particularly participants, were less likely to select this option, with this trend being accentuated moving up the risk categories. The inverse of this trend was true for the item 'connecting with others', with males across the six risk profiles reporting large negative residuals $(-4.4$ to -8.7$)$ and females, particularly participants, reported large residuals (-0.4 to 1.4 for non-participants, and 5.6 to 7.9 for participants).

\section{Qualitative Analysis}

There were 24 participants across three traditional focus groups, with an additional thirteen PEIA members providing feedback in a more informal setting. Due to logistical limitations, demographic data was not collected for these members, and demographic reporting reflects the 24 focus group participants only. Five participants were between the ages of 18-34, ten were between $35-54$, seven between 55-70, and one participant was 70+ years of age (one participant declined to answer). Focus group participants were overwhelmingly female $(n=22)$, and were obese based on average $\mathrm{BMI}(M=30.09, \mathrm{SD}=7.85)$. Similar to the survey respondents, familiarity with PEIA programming was low $(M=2.5, \mathrm{SD}=1.02$; measured using the same 5-point likert scale), and a limited number of participants had previously engaged in programming sponsored by PEIA ( $n=1$ for the Weight Management Program; $n=13$ for "other 
wellness program offered at worksite"). The total number of codes across the four transcripts was 344. The first focus group ( $n=5$ participants) had 85 codes, the second group $(n=10)$ had 105 codes, the third group $(n=9)$ had 116 codes, and the final site visited $(n=13)$ produced 38 codes.

Looking at the higher- and second-order themes, $8.1 \%(n=28)$ of the codes fell into the 'previous experience with WWPs' category. Consistent with participants' responses on the demographic survey, discussion of previous experience in WWPs was limited. The most common experiences were either group exercise classes including on-site walking groups, Zumba or circuit training with coworkers after work, or Weight Watchers (e.g., related to group classes "We had one every year... for several years, we did walking, we did exercise balls.") Participants also discussed having participated in PEIA's “Improve Your Score” program in the past. Overall, $7.3 \%(n=25)$ of the codes fell into the "current health behaviors" category. Of the current health behaviors that were reported by focus group participants, the most common were trying to drink more water, particularly to replace regular and diet pop, as well as exercising, mostly in the form of walking (e.g., “... I usually try and drink a lot of water, I try not to drink soda ever, and if I drink juice, I try and make sure it's actually juice and not just sugar water.")

The information on preferences related to wellness programming was more robust, with $37.2 \%(n=128)$ of the codes relating to what aspects of wellness programming would be most appealing to them and what they would want to see PEIA offer. The elements that received the most consistent endorsement were tailoring programs to fit the needs and desires of employees (e.g., "if it was toning and stretching..., whatever, fit it to what the employees want."), education in the form of information, feedback on progress, and coaching (e.g., "When I got my letter 
stating "you're in the red"... so what, do I google that? I can do that any day. We just need more education."), and that programs needed to be convenient (e.g., "Knowing that something is right here on our site that we can offer is just big for me. I travel back and forth each day... and your day is mostly eaten up by the time you travel to and from [work]"). Other topics that were highlighted repeatedly included providing accountability within the program and creating programs with social support in mind.

Incentives made up $20.3 \%(n=70)$ of total codes, with a few themes emerging from within the higher order code. Monetary incentives (e.g., cash, gift cards, vouchers) and discounts on insurance costs were highlighted repeatedly across the various focus groups, with participants suggesting that the external incentives be limited to wellness-related items (e.g., "... even grocery vouchers, you know, for a free head of broccoli. So it won't be just any kind of vegetable, it'll be certain vegetables.”; “ ...that could be an incentive! A discount on shoes at a particular store, like Dicks Sporting Goods.”). Participants also suggested repeatedly that the incentive should be tied to outcomes (e.g., lab values, weight loss, etc.) in order to incentivize people to work towards improving their health (e.g., "... lets just say if you lost a certain percentage of your body fat, why don't they give you more of a discount? I mean, our insurance is a lot. You know, if they give you an incentive to keep being healthy... that would be a good incentive to keep me on track!").

Participants also spoke about being motivated by improving their lab values, seeing results (e.g., losing weight), and of the satisfaction that comes with seeing progress (e.g., “... as you get older, and there are health issues, blood pressure, cholesterol, that should be a really strong incentive"; “... that innate incentive, is just being able to see that you've lost weight, or that you're feeling better." The connection between feeling better and healthy behaviors came 
up in all four focus groups, and was often connected with a shift in mindset to where wellness participants might want to participate instead of feel coerced (e.g., "but that's where it starts working I think, is when people actually want to get healthy and do it for the right reasons."; "I think everybody has to find their 'why'. Why they want to get healthier, why they want to live one more day, you know...”). Social support, and the accountability that comes with making healthy decisions as a group was also a repeated theme across the focus groups (e.g., "it motivates you. I find it easier to exercise if I'm with a couple other people than to do it myself."; “you don't have time to interact with other employees until, if we do something like [after-work group classes], I feel like I get to spend time with them.”).

Participants also identified a number of barriers associated with participating in wellness programming, with $19.2 \%(n=66)$ of the overall codes relating to anything that might get in the way of participating in wellness programming. The most reported theme was a lack of knowledge about what is offered to them as state employees, how to access that information, or how to get started once they had that information (e.g., “...from my perspective I wouldn't know that PEIA offered anything."; "you had to do certain things to even get your \$10 dollar discount after you did your screening! And that, you only knew to do that if you heard it through the grapevine". Other barriers that were identified included technology (e.g., "...there are a lot of employees who don't have computers at home”), time (e.g., “...once I get home, it’s a drag to make myself go back out"), and access to programming, particularly for employees in rural areas.

A small portion of the codes were associated with contact preferences $(7.8 \% ; n=27)$, and they presented a lack of consensus related to how people want to receive their wellness information. All of the focus groups highlighted the importance of meeting with wellness 
professionals face-to-face to begin with, however participants were split in opinion after initial contact. Some thought follow-up would work best via e-mail and internet resources (e.g., "... definitely the in-person is very beneficial, particularly in the beginning, but then web resources, where a person can go on their own and check out different programs."), while others felt that e-mail was too overwhelming and preferred memos or mailings they could physically interact with (“...if I get something in e-mail and I just don't have time to read it, I just click past it and never go back"; "I prefer a piece of paper... if they tell me I have to go online, I may forget."). Participants were also split on the frequency of contact, with some suggesting that the more frequent they are notified about wellness programming, the more likely they are to stay engaged, and others suggesting that too much was simply too much.

\section{Summary}

Preferences across both the quantitative and qualitative portion of the study matched in some ways, with both respondents and focus group participants highlighting on-site fitness classes and access to a subsidized gym membership as valuable support from their employer. Fewer nutrition preferences emerged from the focus groups, but consistent with respondents desire to see fruit and vegetable discount programs, some of the focus group participants suggested gift cards for healthy restaurant meals or vouchers for healthy grocery items.

Incentives tended to match across data sources as well, with focus group participants echoing the survey results by suggesting a discount on insurance costs would be a very strong motivator for participation. Social support was also highlighted in both the quantitative and qualitative findings, both as a preference for how WWPs are designed, as well as an incentive to participate in programming. One theme that was unmeasured on the survey, but was consistent in the focus groups was the suggestion that something has to "click" with the individual in order 
for them to be successful in changing their habits or developing a healthier lifestyle. For many of the participants, this was associated with a shift away from healthy behaviors as something they "had to do", and instead as something they had the chance to do and made them feel better and more satisfied.

One significant discrepancy that existed between survey results and the focus groups was the idea of connecting incentives to progress or results in wellness programming. Based on the risk profile analysis, it could be inferred that a discount on insurance premiums or wellness points for completing programs were more appealing options for 'no risk' respondents who would not have much work to do to qualify for their discount. This sentiment was not mirrored in the focus groups, where participants suggested that in order to stay motivated and achieve success in WWPs, they should be incentivized based on their progress and results. A lack of consensus also occurred when looking at preferences related to delivery methods for wellness programming. Survey respondents reported that a personalized webpage and e-mail were valuable tools in communicating wellness information, however in the focus groups, participants continually highlighted technology, whether it was e-mail or web-based, as a barrier that would prevent them from interacting with wellness programming.

Aspects of the wellness survey, as well as the environmental evaluation provided a better understanding of the worksite environment, and what types of programming would be possible. These results highlighted several conflicts that exist between what state employees want and what is feasible given the built environment. Particularly, employees highlighted on-site fitness classes as a preferred wellness program, but only a limited number of employees reported having the space for classes like this to take place. Although this preference was echoed in the focus groups, the $\mathrm{CDC}$ evaluation reinforced the notion that worksites do not have the elements in 
place to properly implement on-site classes. The brief assessment of worksite features suggested that the two most prominent elements were space to walk, and access to safe, unflavored drinking water at no cost. Encouragingly, two of the most consistently reported health behaviors across the focus group participants were walking and increasing their water intake, which may provide a useful starting point when looking at how to promote healthy behaviors moving forward.

\section{Discussion}

Throughout the literature, tailoring of programs to participants' needs and wants has consistently resulted in increased engagement and positive outcomes (Hutchinson \& Wilson, 2011). Using the idea of tailoring as a starting point, the current study aimed to better conceptualize what state employees wanted when it came to wellness programming. Focus group participants reinforced this idea by suggesting that wellness information and programming should be specific to their needs, and that if programs felt like they were "one size fits all", that they would be less likely to get involved or maintain their participation.

Overall, general interest in programming was high across nutrition, physical activity, and stress management programs, and key details regarding respondent preferences emerged. Both survey respondents and focus group participants reported low familiarity with the programming offered by the agency, which suggests that despite high interest in programming, most of the employees involved in the study did not know how to participate. Previous research has highlighted a lack of knowledge related to wellness programming as a significant barrier to participation (Linnan, Sorensen, Colditz, Klar, \& Emmons, 2001). This theme was emphasized heavily during focus groups, during which employees reported not knowing what the agency offered, what was available in their area, and not knowing how to receive incentives even if they 
had participated. Focus group participants also commented that programming needed to do a better job of connecting employees with specific ways they could improve their health, and that without the "education" piece, many people lacked the skills to build a healthy lifestyle.

The emphasis on the lack of education and the skills needed to make healthy behavior change speaks to a larger issue in wellness programming. Although nearly $70 \%$ of the survey respondents reported that they were interested in a discount on their premium as an incentive for participating in wellness programming, and focus group participants suggested that this discount be tied to specific outcomes (e.g., decreases in weight, cholesterol, blood pressure), there is growing concern related to whether or not these types of incentives are ethical (Horwitz, Kelly, \& DiNardo, 2013). More specifically, some researchers suggest that tying a discount to health outcomes in WWP makes the unfair assumption that everyone has the opportunity and the ability to make healthy behavior change (Schmidt, Voigt, \& Wikler, 2010). When looking at preferences for a premium discount in the current study, there was a clear gap between those who had no reported health risks and those who were classified as moderate or high risk, with interest dropping sharply within the group of employees who were currently dealing with health conditions. These results may suggest that employees who are already dealing with health conditions may perceive a discount to be unfair or unappealing since they may not believe they are capable of succeeding in a program and being rewarded with a discount. Congruent with this idea, some focus group participants reported that they were discouraged from participating in programming when they knew they had not made progress between health screenings, reinforcing the notion that connecting incentives to specific outcomes might serve to highlight an employee's inability to change their behavior if they lack the skills or support to be successful. 
Lewis and colleagues (1996) had previously reported that employees with a number of risk factors are less likely to participate in wellness programming, however this was not reflected in the preferences reported in the current study. Employees were more likely to indicate interest in all three of the general wellness categories as risk increased, which suggests that the survey sample, particularly those with a number of health risk factors, are interested in improving their health, but may face barriers that prevent them from participating. Previous research has suggested that socioeconomic status remains a significant barrier to WWP participation, and the results of the current study reinforce the notion that employees who have money are more likely to have previously participated in wellness programming (Merrill \& Hull, 2013). This pattern is especially concerning because low income employees, who are more likely to have health risks to begin with, could benefit greatly from effective wellness programming (Link \& Phelan, 1995). Taken together, these results point to the fact that interest is high in a section of the workforce that has not been reached by wellness programming, and creative ways to reach this population and programming tailored to their needs may result in positive outcomes.

When looking for ways to improve programming to increase participation, one of the consistent themes in the current study, particularly for females, was the use of social support. Both respondents and participants spoke to the importance of connecting with others as part of the structure of WWPs and the accountability that comes with making behavior change with other people. This theme echoes previous research into the importance of social support, not only for successful behavior change, but also as an intervention in itself, with support being positively related to a number of health outcomes (Uchino, Cacioppo, \& Kiecolt-Glaser, 1996). Focus group participants also emphasized the importance of a healthy culture at their worksite (e.g., replacing a bowl full of candy with fresh fruit) to reinforce individuals as they work 
towards a healthier lifestyle, which is congruent with social ecological models of health behavior change, as well as previous programs that have taken an environmental approach to improving employees' health behaviors (LeCheminant \& Merrill, 2012; Stokols, 1996). However, men were much less likely to identify social support as motivating, which fits with previous research that suggests that women resonate more with that aspect of wellness programming (Werneburg et al., 2011). When looking at ways to encourage males to engage in WWPs, Morgan and colleagues (2011) strategy of using cooperation and competition may be effective. Shift-work crews were rewarded for having the highest average percentage of weight loss when compared to other crews, which provided both a sense of teamwork, as well as the external incentive of beating others. Finding ways to foster healthy competition within the workplace (i.e., Maintain Don't Gain programs, The Biggest Loser competitions, etc.) may be a way to engage men who might otherwise not participate in wellness programming.

The interest in social support also illuminated another barrier that significantly impacts the implementation of WWPs. Although social support emerged as an important preference, support groups related to nutrition and physical activity were not present at an overwhelming majority of the worksites. This finding was consistent across other preferences as well, with onsite fitness classes being one of the highest rated physical activity preferences, and a large majority of respondents reporting that their worksite lacked the space for these classes. While the primary purpose of the current study was not to investigate the environmental barriers associated with implementing wellness programs, the results suggest that many of the worksites across the state do not have the built environment or worksite culture that would allow for many of the programs to be implemented. Campaigns or policies that could reduce or eliminate these environmental and cultural barriers could have wide impact. 
The most promising interventions that emerged are likely the simplest. One of the most consistently reported worksite features was access to safe, unflavored drinking water at no cost. This was also brought up repeatedly in focus groups as one of most common health behaviors that individuals were trying to implement. While water itself is an important nutrient, recent studies have shown the effectiveness of replacing sugar sweetened beverages with water as an effective method of weight loss (Daniels \& Popkin, 2010). Drinking water prior to meals has also been shown to encourage weight loss (Dennis, et al., 2010). This may mean that interventions aimed at increasing employees' water intake, particularly when water is substituted for high calorie drinks, may be a useful intervention moving forward.

Similar to the availability of drinking water, a safe place to walk in or around the worksite was the most prevalent physical activity feature at worksites, and also received consistent endorsement from focus group participants. Current research supports the efficacy of organizing walking groups as a way to increase overall physical activity, which in turn may improve fitness and result in weight loss (Kassavou, Turner, \& French, 2013). Thus, interventions aimed at increasing both employees walking and water intake may be cost-effective and impactful, in that they are not complicated, do not require changing the built environment of the worksite, and may resonate with the behaviors employees are already working to change. However, it is important to note that while a safe place to walk and access to drinking water were the most prevalent worksite features, a majority of respondents reported not having access to these features, which only serves to highlight the fundamental environmental barriers faced by WWPs.

Another significant barrier that was repeated in a number of the focus groups was a lack of program availability, particularly in rural areas of West Virginia. Programming offered by the 
agency has utilized technology in the past (e.g., telephone-based health behavior counseling) in an effort to overcome some of these barriers. Previous literature has also pointed to possibility that technology could be used to deliver tailored information and interventions more effectively (Eisen et al., 2008). One of the aims of the current study was to get a better understanding of state employees' preferences related to contact and delivery methods related to wellness information, so that future programs could take advantage of technology in a way that would be utilized by potential participants. The results of the study did not provide a clear consensus related to how state employees would like to consume their wellness information. A personalized webpage was the most preferred delivery method, however many of the focus group participants suggested that putting information online was a barrier to their participation. This pattern was repeated with e-mail communication, with e-mail being the second highest rated delivery method but with many participants suggesting that e-mails get lost in the shuffle. The contradictory nature of participants' opinions may speak to the need to offer a number of methods for employees to connect with their wellness information rather than finding a single method that will work for most. The case could be made that different segments of employees will be successfully reached via e-mail or a webpage, others with text messages, and some may require face to face interaction or paper-based communication in order to feel connected to their programming. One possible way of satisfying some employees' desire to connect with a real person, instead of e-mail or text communications, may be to provide a wellness coaching hotline, which would allow state employees access to real-time coaching and advice without forcing all employees to engage in that way. Additionally, if the agency were interested in developing content for a wellness newsletter, they might find success in allowing employees to decide if 
they wanted it delivered in the mail or to their workplace, or if they would prefer the information in an e-mail or through text message reminders.

The current study had a number of limitations that need to be kept in mind when drawing conclusions from the results. First, the survey was disseminated using e-mails that were provided to the agency, which impacted the sample that had an opportunity to take the survey. Similarly, the survey was administered online, which may have presented a barrier to some state employees, and likely skewed the results, particularly regarding the questions about technology use and preference. Second, although worksite coordinators were encouraged to recruit a variety of participants for the focus groups, the participants were volunteers, which may have resulted in self-selection bias. On average, the survey sample was more educated and reported higher income levels when compared to West Virginia as a whole, which likely influenced the results, and limits the generalizability of the survey results. Similarly, the focus group participants were almost entirely female, which limits the generalizability of their responses. It is also important to note that many of the questions on the wellness survey required respondents to self-report (e.g., health risks, current health behaviors), which impacts the accuracy of the results and subsequent conclusions.

Although the current study sought to gain insight into the preferences of state employees related to wellness programming, a number of important questions have emerged that require future research. Specifically, while preference data was collected, the current study did not look at the underlying mechanisms behind why certain programs were more highly rated than others. In order to develop effective interventions, researchers and practitioners should identify the aspects of these programs that employees find most appealing so that they can be replicated more consistently. There were also some important differences that emerged when preferences for 
incentives and programming were examined across gender, previous participation, and risk profiles. Future studies should attempt to better understand the preferences of employees who may be less "reachable" (e.g., high risk, non-participants, males) in an effort to increase participation for all employees. Lastly, a more dedicated feasibility assessment regarding the use of technology in delivering wellness programming may help to provide a clearer understanding of whether or not employees would be willing to participate in novel approaches to program delivery (e.g., web-based content, text message reminders, etc.).

The purpose of worksite wellness programming is above all to provide the resources and opportunities for employees to lead happier and healthier lives. The current study provides the opportunity to better understand how employees would like to go about the process of improving their health, but the real bottom line is that the interest and energy is there if future programs can find a way to capture it. In the context of the obesity epidemic, the pervasiveness of diseases caused by poor lifestyle decisions, and rising health care costs, the moral obligation lies with those in power to harness the innate human desire to move towards health and provide the means for individuals to reach this goal. 


\section{References}

Baicker, K., Cutler, D., \& Song, Z. (2010). Workplace wellness programs can generate savings. Health Affairs 29(2), 304-311. doi: 10.1377/hlthaff.2009.0626

Bearden, J. (2010). Chi-square Test of Independence. Retrieved from: http://www.geneseo.edu/ bearden/socl211/chisquareweb/chisquare.html

Bodenheimer, T., Chen, E., \& Bennett, H. D. (2009). Confronting the growing burden of chronic disease: can the U.S. health care workforce do the job? Health Affairs, 28(1), 64-74. doi: 10.1377/hlthaff.28.1.64

Centers for Disease Control and Prevention. (2011). The community guide. Available at http://thecommunityguide.org/index.html. Accessed October 8, 2013.

Chapman, L. S. (2005). Meta-evaluation of worksite health promotion economic return studies: 2005 update. American Journal of Health Promotion, 19(6), TAHP1-TAHP10. http://dx.doi.org/10.4278/0890-1171-19.6.TAHP-1

Conn, V. S., Hafdahl, A. R., Cooper, P. S., Brown, L. M., \& Lusk, S. L. (2009). Meta-analysis of workplace physical activity interventions. American Journal of Preventive Medicine, 37(4), 330-339. http://dx.doi.org/10.1016/j.amepre.2009.06.008

Cook, C., Heath, F., \& Thompson, R. L. (2000). A meta-analysis of response rates in web- or internet-based surveys. Educational and Psychological Measurement, 60(6). 821-836. doi: $10.1177 / 00131640021970934$

Creswell, J. W. (2013). Qualitative inquiry and research design: choosing among five approaches $\left(3^{\text {rd }}\right.$ ed.). Thousand Oaks, CA: SAGE Publications. 
Daniels, M. C., \& Popkin, B. M. (2010). Impact of water intake on energy intake and weight status: a systematic review. Nutrition Reviews, 68(9), 505-521. doi: 10.1111/j.17534887.2010.00311.x

Dennis, E. A., Dengo, A. L., Comber, D. L., Flack, K. D., Savla, J., Davy, K. P., \& Davy, B. M. (2010). Water Consumption Increases Weight Loss During a Hypocaloric Diet Intervention in Middle-aged and Older Adults. Obesity, 18(2), 300-307. doi: 10.1038/oby.2009.235

Dillman, D. A. (2000). Mail and internet surveys: the tailored design method (2 ${ }^{\text {nd }}$ Ed.). New York, NY: John Wiley \& Sons.

Eisen, K. P., Allen, G. J., Bollash, M., \& Pescatello, L. S. (2008). Stress management in the workplace: a comparison of a computer-based and an in-person stress-management intervention. Computers in Human Behavior, 24, 486-496. http://dx.doi.org/10.1016/j.chb.2007.02.003

Horwitz, J. R., Kelly, B. D., \& DiNardo, J. E. (2013). Wellness incentives in the workplace: cost savings through cost shifting to unhealthy workers. Health Affairs, 32(3), 468-476. doi: 10.1377/hlthaff.2012.0683

Hutchinson, A. D., \& Wilson, C. (2011). Improving nutrition and physical activity in the workplaces: a meta-analysis of intervention studies. Health Promotion International, 27(2), 238-249. doi: 10.1093/heapro/dar035

Kassavou, A., Turner, A., \& French, D. P. (2013). Do interventions to promote walking in groups increase physical activity? A meta-analysis. International Journal of Behavioral Nutrition and Physical Activity, 10(18). doi: http://dx.doi.org/10.1186/1479-5868-10-18 
LeCheminant, J. D., \& Merrill, R. M. (2012). Improved health behaviors persist over two years for employees in a worksite wellness program. Population Health Management, 15(2), 261266. doi: 10.1089/pop.2011.0083

Lewis, R. J., Huebner, W. W., Yarborough III, C. M. (1996). Characteristics of participants and nonparticipants in worksite health promotion. American Journal of Health Promotion, 11(2), 99-106. http://dx.doi.org/10.4278/0890-1171-11.2.99

Link, B. G., \& Phelan, J. (1995). Social Conditions as Fundamental Causes of Disease. Journal of Health and Social Behavior, 35, 80-94. http://dx.doi.org/10.2307/2626958

Linnan, L. A., Sorensen, G., Colditz, G., Klar, N., \& Emmons, K. M. (2001). Using theory to understand the multiple determinants of low participation in worksite health promotion programs. Health Education \& Behavior, 28(5), 591-607. doi:

\section{$10.1177 / 109019810102800506$}

Loeppke, R., Edington, D. W., \& Bég, S. (2010). Impact of the prevention plan on employee health risk reduction. Population Health Management, 13(5), 275-284. doi:10.1089/pop.2010.0027

Loeppke, R., Edington, D., Bender, J., \& Reynolds, A. (2013). The association of technology in a workplace wellness program with health risk factor reduction. Journal of Occupational and Educational Medicine, 55(3), 259 - 264. doi: 10.1097/JOM.0b013e3182898639

Loveman, E., Frampton, G. K., Shepherd, J., Picot, J., Cooper, K., Bryant, J... Clegg, A. (2011). The clinical effectiveness and cost-effectiveness of long-term weight management schemes for adults: a systematic review. Health Technology Assessment, 15(2), 1-182. doi: $10.3310 /$ hta15020 
Mattke, S., Liu, H., Caloyeras, J. P., Huang, C. Y., Van Busum, K. R., Khodyakov, D., \& Shier, V. (2013). Workplace wellness programs study: final report. Santa Monica, CA: The RAND Corporation.

Merrill, R. M., \& Hull, J. D. (2013). Factors associated with participation in and benefits of a worksite wellness program. Population Health Management, 16(4), 221-226. doi:10.1089/pop.2012.0064

Mokdad, A. H., Marks, J. S., Stroup, D. F., \& Gerberding, J. L. (2004). Actual causes of death in the United States, 2000. The Journal of the American Medical Association, 291(10), 12381245. doi:10.1001/jama.291.10.1238

Moran, A. E. (2013) Wellness programs after the Affordable Care Act. Employee Relations Law Journal, 39(2), 75-83. Retrieved from http://search.ebscohost.com/login.aspx?direct=true $\& d b=s 3 h \& A N=89484610 \&$ site=ehostlive

Morgan, P. J., Collins, C. E., Plotnikoff, R. C., Cook, A. T., Berthon, B., Mitchell, S., \& Callister, R. (2011). Efficacy of a workplace-based weight loss program for overweight male shift workers: The workplace POWER (Preventing Obesity Without Eating like a Rabbit) randomized controlled trial. Preventive Medicine 52(5), 317-325. http://dx.doi.org/10.1016/j.ypmed.2011.01.031

Norman, P., Boer, H., \& Seydel, E. R. (2005). Protection Motivation Theory. In: M. Conner and P. Norman (eds.), Predicting health behaviour: research and practice with social cognitive models (pp. 81 -126). Maidenhead: Open University Press. 
Pappachan, M. J. (2011). Increasing prevalence of lifestyle diseases: high time for action. Indian Journal of Medical Research, 134(2), 143-145. Retrieved from http://www.ncbi.nlm.nih.gov/pmc/articles/PMC3181012/

Pathways to Wellness. (2014). In PEIA: Health and Wellness Programs. Retrieved from: http://www.peia.wv.gov/healthinformation/health_and_wellness_programs/Pages/default.aspx

Person, A. L., Colby, S. E., Bulova, J. A., \& Eubanks, J. W. (2010). Barriers to participation in a worksite wellness program. Nutrition Research and Practice, 4(2), 149-154. doi: 10.4162/nrp.2010.4.2.149

Robroek, S. J. W., van Lenthe, F. J., van Empelen, P., \& Burdorf, A. (2009). Determinants of participation in worksite health promotion programmes: a systematic review. International Journal of Behavioral Nutrition and Physical Activity, 6(26). doi: 10.1186/1479-5868-6-26

Rongen, A., Robroek, S.J.W., van Lenthe, F. J., \& Burdorf, A. (2013). Workplace health promotion: A meta-analysis of effectiveness. American Journal of Preventive Medicine, 44(4), 406-415. http://dx.doi.org/10.1016/j.amepre.2012.12.007

Ross. C. E., \& Wu, C. (1995). The links between education and health. American Sociological Review, 60, 719-745. Retrieved from http://www.jstor.org/stable/2096319

Ryan, R. M., Patrick, H., Deci, E. L., \& Williams, G. C. (2008). Facilitating health behaviour change and its maintenance: interventions based on self-determination theory. The European Health Psychologist, 10, 2-5. Retrieved from http://www.ehps.net/ehp/issues/2008/v10iss1_March2008/EHP_March_2008_All.pdf 
Schmidt, H., Voigt, K., \& Wikler, D. (2010). Carrots, Sticks, and Health Care Reform Problems with Wellness Incentives. The New England Journal of Medicine, 362(2). http://dx.doi.org/10.1056/NEJMp0911552

Serxner, S. A., Gold, D. B., Grossmeier, J. J., \& Anderson, D. R. (2003). The relationship between health promotion program participation and medical costs: A dose response. Journal of Occupational and Environmental Medicine, 45, 1196-1200. http://dx.doi.org/10.1097/01.jom.0000095002.12772.6a

Sorensen, G., Linnan, L., \& Hunt, M. K. (2004). Worksite-based research and initiatives to increase fruit and vegetable consumption. Preventive Medicine, 39, S94-S100. http://dx.doi.org/10.1016/j.ypmed.2003.12.020

Sorensen, G., Stoddard, A., Peterson, K., Cohen, N., Hunt, M. K., Stein, E., . . Lederman, R. (1999). Increasing fruit and vegetable consumption through worksites and families in the Treatwell 5-a-Day Study. American Journal of Public Health, 89(1), 54-60. doi: 10.2105/AJPH.89.1.54

Stokols, D. (1996). Translating social ecological theory into guidelines for community health promotion. American Journal of Health Promotion, 10(4), 282-298. http://dx.doi.org/10.4278/0890-1171-10.4.282

Uchino, B. N., Cacioppo, J. T., \& Kiecolt-Glaser, J. K. (1996). The Relationship Between Social Support and Physiological Processes: A Review With Emphasis on Underlying Mechanisms and Implications for Health. Psychological Bulletin, 119(3), 488-531. doi: 10.1037/00332909.119.3.488

Wantland, D. J., Portillo, C. J., Holzemer, W. L., Slaughter, R., \& McGhee, E. M. (2004). The effectiveness of web-based vs. non-web-based interventions: a meta-analysis of behavioral 
change outcomes. Journal of Medical Internet Research, 6(4), e40. doi:

10.2196/jmir.6.4.e40

Werneburg, B. L., Herman, L. L., Preston, H. R., Rausch, S. M., Warren, B. A., Olsen, K. D., \& Clark, M. M. (2011). Effectiveness of a Multidisciplinary Worksite Stress Reduction Programme for Women. Stress and Health, 27, 356-364.

http://dx.doi.org/10.1002/smi.1380

Wolever, R. Q., Bobinet, K. J., McCabe, K., Mackenzie, E. R., Fekete, E., Kusnick, C. A., \& Baime, M. (2012). Effective and viable mind-body stress reduction in the workplace: a randomized controlled trial. Journal of Occupational Health Psychology, 17(2), 246-258. doi: $10.1037 / \mathrm{a} 0027278$ 
Table 1

A Comparison of Wellness Survey Responses with the General West Virginia Population

$\begin{array}{cccc}\text { Demographic Variables } & \text { Wellness Survey } & \text { West Virginia } & \text { Relative Difference } \\ & (\%) & \text { Residents }(\%) & (\%)\end{array}$

\begin{tabular}{|c|c|c|c|}
\hline High School Graduates $^{b}$ & 99.7 & 83.4 & +20 \\
\hline College Graduates $^{\mathrm{b}}$ & 64.2 & 17.9 & +259 \\
\hline Obesity $(\mathrm{BMI}>30)^{\mathrm{a}}$ & 38.6 & 32.4 & +19 \\
\hline Overweight and Obese $(\mathrm{BMI}>25)^{\mathrm{a}}$ & 69.1 & 68.9 & -- \\
\hline Hypertension $^{\mathrm{a}}$ & 29.9 & 37.0 & -19 \\
\hline High Cholesterol $^{\mathrm{a}}$ & 26.7 & 40.5 & -34 \\
\hline Diabetes $^{\mathrm{a}}$ & 11.0 & 12.0 & -8 \\
\hline Meeting Fruit and Vegetable & 8.2 & 8.3 & -- \\
\hline \multicolumn{4}{|l|}{ Guidelines $(>5 / \text { day })^{\mathrm{a}}$} \\
\hline Meeting Physical Activity & 16.9 & 43.0 & -61 \\
\hline \multicolumn{4}{|l|}{ Guidelines $(>150 \mathrm{~min} / \text { week })^{\mathrm{a}}$} \\
\hline Meeting Strength Training & 31.2 & 20.2 & +54 \\
\hline
\end{tabular}

Note. The 'relative difference' calculation refers to relative change from the population data. For example, for obesity, the absolute difference is +6.2 but relative to the norm of $32.4 \%$, this represent a $19 \%$ change in reported obesity in the sample

${ }^{a}$ Information retrieved from the West Virginia BRFSS 2011

${ }^{\mathrm{b}}$ Information retrieved from the U.S. Census Bureau 
Table 2

Income Stratification for Survey Respondents and West Virginian Residents Income Wellness Survey West Virginia Residents ${ }^{\mathrm{a}}$

Less than $\$ 25,000$

6.3

38.3

$\$ 25,001$ to $\$ 50,000$

36.5

33.6

$\$ 50,000+$

28.1

Note. 9.9\% $(n=1709)$ of the respondents chose 'I would prefer not to answer' for the income item, and another $8.0 \%(n=1497)$ did not answer the item. Percentages were calculated after excluding those respondents.

${ }^{\mathrm{a}}$ Information retrieved from the West Virginia BRFSS 2011 
Table 3

Preferences for Nutrition, Physical Activity, and Stress Management Programs

Programming

Interest in Nutrition Programming

- A fruit and vegetable discount program

- Your own personalized webpage with a food log

- In person classes related to buying and preparing healthy food

19.8

- Home gardening programs

19.

Interest in Physical Activity Programming

- A discount on gym memberships in your community

- A pedometer to track your steps throughout the day

- In person exercise classes offered at your worksite

- Your own personalized webpage with an exercise log

Interest in Stress Management Programming

- In person stress management classes

- Relaxation audio files

- Text messages related to your stress management goals

- Podcasts that provide tips on how to reduce your stress 
Table 4

Delivery preferences of respondents

Delivery Method

$M \quad S D$

A personalized webpage with resources related to your health

2.58

1.09

E-mails with educational information and links to web resources

2.53

1.05

An interactive app for your smart phone

2.21

1.20

Talking with someone in person

1.99

1.02

Text messages to remind me of my health goals

1.81

1.03

Talking with someone on the phone

1.70

0.91

Note. Delivery preferences were measured from 1 (not at all interested) to 4 (very interested) 
Table 5

Respondents' Preferred Incentives

External Incentives

- Receiving a discount on your insurance premium $\quad 69.6 \%$

$\begin{array}{ll}\text { - Cash or gifts } & 11.4 \%\end{array}$

- Getting time off to participate in wellness programming at your worksite $\quad 10.4 \%$

- Getting 'wellness points' for completing programs, and exchanging them for gift $\quad 7.9 \%$ cards or prizes

- Being enrolled in a drawing to win prizes $\quad 0.6 \%$

Intrinsic Incentives

- Learning new skills related to being healthy $32.6 \%$

- Connecting with other coworkers to build support for better health in your life $\quad 25.9 \%$

- None of these would encourage me to start or continue a wellness program $\quad 22.6 \%$

- Getting to make choices about how and when you choose to be healthy $\quad 18.9 \%$

Note. Respondents could only select their "most preferred" incentive for each item 
Table 6

Worksite Availability from the Wellness Survey

Worksite Option

A safe place to walk at your worksite (indoor or outdoor)

$41.1 \%$

- A path or route for walking safely outdoors

- A path to walk safely indoors

Safe, unflavored drinking water for employees at no cost

An on-site cafeteria with healthy food choices

A fitness facility or space for on-site physical activity classes

Flexible work arrangements or breaks for physical activity

$10.3 \%$

On-site vending machines with healthy food and beverage choices

$6.4 \%$

Support groups or clubs to encourage healthy eating at your workplace

$3.9 \%$

Support groups or clubs to encourage physical activity at your workplace

$3.6 \%$

Note. Respondents were asked to select any of the options which were present at their worksite 
Table 7

CDC Environmental Evaluation - Nutrition Features

Item $M \quad$ SD

Nutrition

Refrigerator Access

Microwave Access

Sink Access

Safe, unflavored drinking water at no cost

Support breastfeeding (i.e., a private space to nurse)

Ban marketing of unhealthy foods

Healthy preparation practices for onsite cafeteria

Smaller portion sizes for onsite cafeteria

Healthy Options in onsite cafeteria

Healthy Options at Company-sponsored Events

Healthy Options in Vending Machines

Healthy purchasing practices for onsite cafeteria

Support for community-wide nutrition opportunities

Nutrition labeling at onsite cafeteria

Pricing strategies that encourage healthy choices
5.00

0.00

5.00

0.00

4.00

2.00

4.00

2.00

3.00

1.63

2.66

2.08

2.66

2.33

2.00

1.00

$1.75 \quad 0.96$

1.75

0.96

1.66

1.15

1.50

1.00

$1.00 \quad 0.00$

$1.00 \quad 0.00$

Note. Delivery preferences were measured from 1 (elements not in place) to 5 (all elements in place) 
Table 8

CDC Environmental Evaluation - Physical Activity Features

Item Mean SD

Physical Activity

Provide flexible work arrangements for PA

Support clubs or groups to encourage PA

A safe area outside to walk or be active

Access to an onsite fitness center or PA classes

Direct support for community-wide PA opportunities

Designate a walking path near the worksite

Promote stairwell use

Encourage non-motorized commutes

Access to a locker room with showers

Enhanc access to public transportation

Activity breaks for meetings longer than an hour

Access to an offsite facility (or subsidized membership)

Access to bicycle parking for employees
$2.25 \quad 0.96$

$2.25 \quad 0.96$

$2.25 \quad 0.96$

$2.25 \quad 1.50$

$2.00 \quad 2.00$

$2.00 \quad 0.81$

$2.00 \quad 1.15$

$1.75 \quad 0.96$

$1.75 \quad 1.50$

$\begin{array}{ll}1.50 & 0.58\end{array}$

$1.25 \quad 0.50$

$1.25 \quad 0.50$

$1.00 \quad 0.00$

Note. Delivery preferences were measured from 1 (elements not in place) to 5 (all elements in place) 
Table 9

Breakdown of Respondents based on Risk and Participation Profiles

Profile

$n$

$(\%)^{\mathrm{a}}$

Non-Participant/No Risk

1604

9.6

Non-Participant/Moderate Risk

1316

7.9

Non-Participant/High Risk

1325

7.9

Participant/No Risk

4317

25.9

Participant/Moderate Risk

3833

23.6

Participant/High Risk

4274

25.6

${ }^{\mathrm{a}}$ Valid percent, which excludes cases without complete risk/participation data

Table 10

Effect Sizes ${ }^{a}$ of the Fixed Factors and Covariate on Delivery Method Preferences

Delivery Method

Risk Profile Gender Age

Text Messages

.008

$.004 \quad .010$

Smart Phone App

.004

$.003 \quad .071$

E-mails with information and links

.005

$.003 \quad .009$

Talking with someone in person

.010

NS $\quad .001$

Talking with someone on the phone

.006

NS $\quad .001$

A personalized webpage

.007

.002

.005

$\mathrm{NS}=p>.05$

${ }^{\text {a }}$ All effect sizes reported as partial $\eta^{2}$

.01 - small; .06-medium; .14 - large 
Table 11

Adjusted Standardized Residuals for General Wellness Program Preferences

\begin{tabular}{ccccc|ccc|ccc|ccc}
\hline \multicolumn{10}{c}{ Preference } & \multicolumn{10}{c}{ Profile } \\
\hline & 1 & 2 & 3 & 4 & 5 & 6 & 7 & 8 & 9 & 10 & 11 & 12 \\
Nutrition & -10.6 & -3.2 & -2.8 & -7 & -0.9 & 1.9 & -5.5 & -0.1 & 0.1 & -1.7 & 5.4 & 11.3 \\
Physical Activity & -9.1 & -4.9 & -6.1 & -6.1 & -1.6 & 0 & -3.4 & -1.2 & -1.6 & 4.2 & 5.8 & 7.8 \\
$\begin{array}{c}\text { Stress } \\
\text { Management }\end{array}$ & -7.4 & -4.4 & -3.5 & -6.3 & -1.7 & 0.2 & -2.6 & 2 & 2.6 & -0.8 & 2.5 & 9.5 \\
\hline
\end{tabular}

Note. The residuals reported are for 'yes' responses. Due to the dichotomous nature of the question, no residuals would simply be the inverse of those displayed here

$1=$ Male/Non-Participant/No Risk

$7=$ Female/Non-Participant/No Risk

$2=$ Male/Non-Participant/Moderate Risk

$8=$ Female/Non-Participant/Moderate Risk

$3=$ Male/Non-Participant/High Risk

$9=$ Female/Non-Participant/High Risk

$4=$ Male/Participant/No Risk

$5=$ Male/Participant/Moderate Risk

$10=$ Female/Participant/No Risk

$11=$ Female $/$ Participant/Moderate Risk

$6=$ Male/Participant $/$ High Risk

$12=$ Female/Participant/High Risk 
Table 12

Adjusted Standardized Residuals for External Incentives

\begin{tabular}{|c|c|c|c|c|c|c|c|c|c|c|c|c|}
\hline \multirow[t]{2}{*}{ Incentive } & \multicolumn{12}{|c|}{ Profile } \\
\hline & 1 & 2 & 3 & 4 & 5 & 6 & 7 & 8 & 9 & 10 & 11 & 12 \\
\hline Cash or Gifts & 1.5 & 2.2 & 0.5 & -1.8 & -1.8 & -2.7 & 4.5 & 4.1 & 2.8 & -0.7 & -1.1 & 2.5 \\
\hline Enrolled in a Drawing & 0.7 & -0.3 & 2.1 & -1.2 & 0 & 0 & 1.1 & -0.7 & 1.8 & -1.3 & 0 & -0.3 \\
\hline $\begin{array}{c}\text { Wellness Points for Completing } \\
\text { Programs }\end{array}$ & -3.1 & 0.4 & -3.1 & -4.7 & -4.1 & -1 & 0.6 & 2.5 & 2.5 & -2.9 & 2.9 & 6.1 \\
\hline Discount on Insurance Premium & 2.9 & -1.1 & -0.5 & 6 & 4.1 & 1.9 & -3.3 & -6 & -5.7 & 5.4 & -1.2 & -4.2 \\
\hline Time Off to Participate & -3.3 & -0.8 & 2.5 & -2.7 & -0.6 & 0.9 & -0.5 & 2.8 & 3 & -4.6 & 0.4 & 3.6 \\
\hline $\begin{array}{l}1=\text { Male/Non-Participant/No Risk } \\
2=\text { Male/Non-Participant/Moderate F } \\
3=\text { Male/Non-Participant/High Risk } \\
4=\text { Male/Participant/No Risk } \\
5=\text { Male/Participant/Moderate Risk } \\
6=\text { Male/Participant/High Risk }\end{array}$ & & $\begin{array}{l}7=\mathrm{F} \\
8=\mathrm{F} \\
9=\mathrm{F} \\
10= \\
11= \\
12=\end{array}$ & $\begin{array}{l}\text { male } \\
\text { male } \\
\text { amale } \\
\text { emal } \\
\text { emal } \\
\text { emal }\end{array}$ & $\begin{array}{l}\text { Non-P } \\
\text { Non-P } \\
\text { Non-P } \\
\text { /Partic } \\
\text { /Partic } \\
\text { /Partic }\end{array}$ & $\begin{array}{l}\text { Irticip } \\
\text { articip } \\
\text { irticip } \\
\text { ipant/ } \\
\text { ipant/ } \\
\text { ipant/ }\end{array}$ & $\begin{array}{l}\mathrm{nt} / \mathrm{Nc} \\
\mathrm{nt} / \mathrm{M} \\
\mathrm{nt} / \mathrm{Hi} \\
\text { Jo Ris } \\
\text { Moder } \\
\text { Tigh F }\end{array}$ & $\begin{array}{l}\text { Risk } \\
\text { derate } \\
\text { h Ris } \\
\text { ite Ris } \\
\text { isk }\end{array}$ & Risk & & & & \\
\hline
\end{tabular}


Table 13

Adjusted Standardized Residuals for Intrinsic Incentives

\begin{tabular}{|c|c|c|c|c|c|c|c|c|c|c|c|c|}
\hline \multirow[t]{2}{*}{ Incentive } & \multicolumn{12}{|c|}{ Profile } \\
\hline & 1 & 2 & 3 & 4 & 5 & 6 & 7 & 8 & 9 & 10 & 11 & 12 \\
\hline Learning New Skills & -3.3 & -2.2 & -0.8 & -1.3 & -0.2 & 0.6 & -0.4 & -1.1 & -1.6 & 0.3 & 2.6 & 2.4 \\
\hline $\begin{array}{c}\text { Getting to Make } \\
\text { Choices }\end{array}$ & -1.7 & 1.7 & 1.5 & -0.3 & 0.6 & 2.2 & -3.4 & 1.9 & 1.9 & -3.7 & -1.1 & 2.6 \\
\hline $\begin{array}{c}\text { Connecting With } \\
\text { Others }\end{array}$ & -6.1 & -5.6 & -8.7 & -7.4 & -4.5 & -4.4 & 1.4 & 0.4 & -0.4 & 7.9 & 5.4 & 5.6 \\
\hline None of These & 11.8 & 6.8 & 8.7 & 9.7 & 4.4 & 1.9 & 2.2 & -1 & 0.5 & -5.2 & -7.6 & -11.1 \\
\hline \multicolumn{3}{|c|}{$\begin{array}{l}2=\text { Male/Non-Participant/Moderate Risk } \\
3=\text { Male/Non-Participant/High Risk } \\
4=\text { Male/Participant/No Risk } \\
5=\text { Male/Participant/Moderate Risk } \\
6=\text { Male/Participant/High Risk }\end{array}$} & \multicolumn{10}{|c|}{$\begin{array}{l}8=\text { Female/Non-Participant/Moderate Risk } \\
9=\text { Female/Non-Participant/High Risk } \\
10=\text { Female/Participant/No Risk } \\
11=\text { Female/Participant/Moderate Risk } \\
12=\text { Female/Participant/High Risk }\end{array}$} \\
\hline
\end{tabular}


Appendix A

PEIA Wellness Survey 
Appendix B

Focus Group Cover Letter 


\section{Dear Participant,}

This letter is to request your participation in a research project to better understand PEIA member's preferences related to worksite wellness programs. This project is being conducted by Peter Kadushin, MS in the department of Sport Sciences with supervision from Dr. Sam Zizzi, a professor in the College of Physical Activity and Sport Sciences, for a Doctoral Degree in Sport and Exercise Psychology. Your participation in this focus group is greatly appreciated and will take about an hour of your time.

Your involvement in this project will be kept as confidential as legally possible and no identifying information will be collected during this session. You must be 18 years of age or older to participate. Your participation is completely voluntary. You may choose not to answer any questions that you do not feel comfortable answering and you may discontinue your participation in this focus group at any time. Your choice to participate or not will not be reported to any of your supervisors. West Virginia University's Institutional Review Board has acknowledgement of this project is on file.

I hope that you will participate in the focus group, as it has the potential to be very beneficial to the development of effective worksite wellness programs. Thank you very much for your time. In the event that you have any questions about this letter or the research project, please feel free to contact Peter Kadushin at (304) 293-4447 or by e-mail at pkadushi@mix.wvu.edu.

Thank you again for your time and your support as we complete this project. It is greatly appreciated.

Sincerely,

Peter Kadushin

Phone: 304-293-7073 Fax: 304-293-3098 http://oric.research.wvu.edu
Chestnut Ridge Research Building

886 Chestnut Ridge Road

PO Box 6845

Morgantown, WV 26506-6845 
Appendix C

Focus Group Script 


\section{Focus Group Script}

1. What are your previous experiences with wellness programs? (previous experience)

2. What do you currently do, if anything, to manage your health? (current behaviors)

3. What types of wellness programs do you think are most beneficial to improving your health? (preferences)

4. What incentives would motivate you to participate in wellness programs, and why? (preferences)

5. What things do you think get in the way of participating in wellness programs? (preferences)

6. If you had a choice, how would you like to receive wellness programming (e.g., in person, over the phone, e-mail), and why? (delivery options/technology) 
Appendix D

Focus Group Demographic Form 


\section{Demographic Information}

Note: Please do not include any identifying information on this form

What is your age?

18-34

$35-54$

$55-70$

$70+$

Gender

Current Height

Current Weight

_ Male

Female

How would you rate your familiarity with the current wellness programs offered by PEIA?

$\begin{array}{lllll}2 & 3 & 4 & 5\end{array}$

(not at all familiar)

(very familiar)

Have you ever participated in the following PEIA wellness programs (select all that apply)?

The Face to Face Diabetes Program

The Weight Management Program

Dean Ornish Spectrum or Dean Ornish Program for Reversing Heart Disease

Other wellness program offered at my worksite 
Appendix E

CDC Environmental Evaluation 
Appendix F

Percentage of Respondents by County 


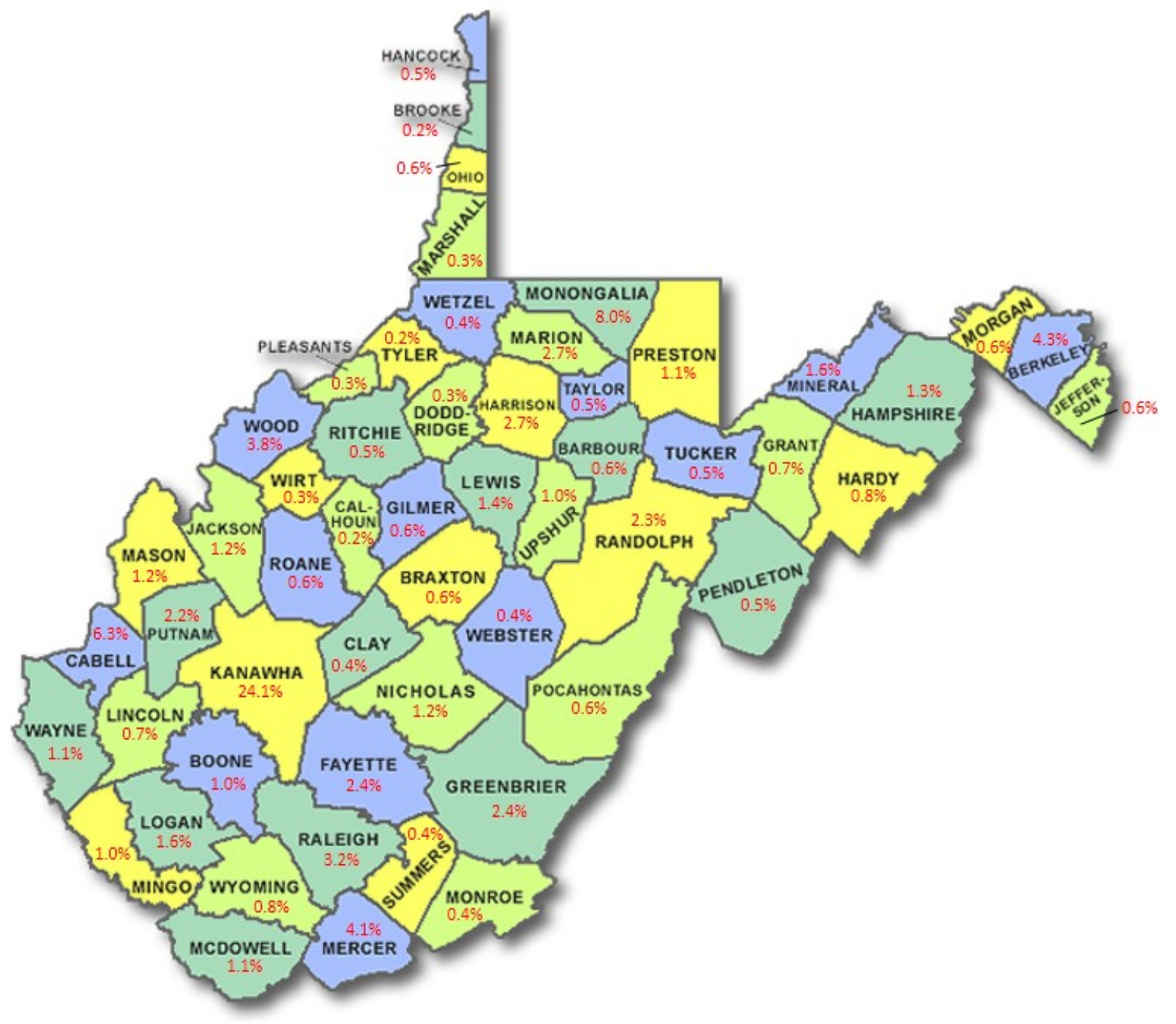


Appendix G

Review of Literature 
Health promotion programs (HPPs) have been utilized by companies in the United States since the late 1970's, and have grown in prominence as healthcare costs have increased and the general health of individuals in the US has decreased. The amount of literature that exists on the topic of HPPs is vast, but often neglects to connect theory with practice. The purpose of this review is to identify the health behavior theories that may apply to participation and effectiveness of HPPs, summarize the financial impact that HPPs can have on employer and healthcare costs, and provide an overview of the clinical effectiveness of HPPs.

\section{Health Behavior Theories}

Health behavior theories are conceptualized in order to provide researchers and interventionists with frameworks through which they might understand how and why make decisions related to their health. While some research does an excellent job of emphasizing the role of theory in the conceptualization, implementation, and evaluation of wellness programs, others lack theory in one or more of these steps. One explanation for the lack of theoretical grounding in worksite wellness programs may be that there is considerable overlap between theories, and no theory has been empirically proven to best explain health behaviors (Noar \& Zimmerman, 2005). It may also be possible that it is simply easier, albeit less effective, to build wellness programs without a rigorous theoretical framework to guide the process. Regardless, understanding how human beings make decisions about their health, and how they begin and maintain health behaviors, is critical to the effectiveness of wellness programs (Webb, Joseph, Yardley, \& Michie, 2010). The following section will review a select number of health behavior theories, including Protection Motivation Theory, Social Cognitive Theory, Self-Determination Theory, and the Social-Ecological Model of Health Promotion. 
Protection Motivation Theory. Protection Motivation Theory (PMT) was originally developed by Rogers (1975) as a way to understand the impact of fear on health decisionmaking, but has since evolved into a social cognitive model that is used to predict health behaviors. The main premise of PMT is that when a message elicits fear in an individual, that person will be motivated to reduce the uncomfortable emotional state. Rogers (1975) made a distinction between the pathways through which an individual can cope with the perception of threat, suggesting that there are both maladaptive (i.e., avoidance) and adaptive (i.e., getting a cancer screening) ways to minimize their discomfort. As the model has evolved, it has come to include a number of mediating constructs, which impact the coping strategies that an individual might employ. These constructs include the individual's perception of the severity of the threat, their vulnerability to that threat, their self-efficacy related to a protective behavior, and the response efficacy of the behavior (Norman, Boer, \& Seydel, 2005). The model has also been divided into the threat appraisal pathway, and the coping appraisal pathway, both of which influence an individual's behavioral intention and the likelihood that they engage in protective behaviors.

The threat appraisal pathway includes an individual's perceptions of severity and vulnerability, factors that either increase or decrease the likelihood of a maladaptive response (Norman et al., 2005). An individual who perceives him or herself to be at risk for developing cardiovascular disease (CVD), for example, and believes that CVD is a significant threat to their health would theoretically be highly motivated to engage in a behavior that reduces their psychological discomfort. The model also accounts for the intrinsic and extrinsic rewards that someone might receive for maladaptive coping or continuing the original behavior, and balances these against perceptions of severity and vulnerability when determining the likelihood of a 
maladaptive coping response. If an individual understands that they are at risk for developing CVD, but also enjoys greasy, high fat foods, they may choose avoidance or denial over a more adaptive coping strategy, thus increasing the likelihood they ignore the health consequences of CVD (Norman, et al., 2005).

In contrast, the coping appraisal pathway looks at factors that increase or decrease the likelihood of an individual engaging in protective behaviors (Norman et al., 2005). The model includes an individual's self-efficacy, or their belief in their ability to engage in a particular coping strategy, along with response efficacy, which is an individual's belief that a particular behavior is effective in impacting the perceived threat. The model suggests that in order for a person to adopt and maintain a low-fat diet that might reduce their risk of CVD, an individual would need to believe they were capable of eating a low-fat diet, and they would also need to believe a low-fat diet does in fact impact CVD risk. Both of these constructs are measured against the response cost of the behavior (i.e., the barriers related to engaging in the behavior), which might also influence a person's decision making (Norman et al., 2005).

All of these constructs come together in the form of protection motivation, or the intention of an individual to engage in a particular behavior. In a number of studies, PMT has been studied in an effort to identify whether it provides an accurate framework for predicting health behaviors (Norman et al., 2005). In a meta-analysis of 65 PMT studies that had to use at least one PMT component and measured intention and/or behavior as the dependent variable, Floyd, PrenticeDunn, and Rogers (2000) found that self-efficacy had the largest effect size with regards to intention and behavior $(d+=.88)$. The studies addressed in the meta-analysis included research on cancer and AIDS prevention, adopting a healthy lifestyle, diet and exercise, and adherence to medical-treatment regimens, as well as others. Overall, the coping appraisal components had 
medium-large effect sizes, while the threat appraisal pathway was associated with small-medium effect sizes (Floyd et al., 2000). The authors also noted that when compared with behavior as the DV, intention produced larger effect sizes, suggesting that PMT components were more effective at predicting intention to act as opposed to actual behavior.

Additional research into the utility of PMT in a physical activity promotion setting was reviewed by Plotnikoff and Trinh (2010), with the authors concluding that across a variety of research designs (e.g., cross-sectional, longitudinal, and intervention), the coping appraisal pathway had the strongest impact on intention to engage in PA. Both the review by Plotnikoff and Trinh (2010) and a subsequent literature review by Bui, Mullan, and McCaffery (2013) of the PA-PMT relationship have suggested that the self-efficacy and response efficacy components of PMT are a good fit for promoting PA, while the threat appraisal pathway may be more appropriate for populations dealing with chronic disease. Even less research has been done using PMT as a framework for promoting nutrition of dietary change. In two studies that aimed to increase participants' consumption of functional foods (i.e., foods that are genetically modified for enhanced physical functioning), the results were consistent with the PA-PMT literature, with intention being the best predictor of behavior, and self-efficacy being the next strongest determinant (Cox, Koster, \& Russell, 2004; Park, Hoover, Dodd, Huffman, \& Feng, 2010).

Several theories of health behavior focus on an individual's perception of a threat and their motivation to protect themselves against the potentially negative consequences of that threat, with PMT and the Health Belief Model sharing a number of similar characteristics in this regard (Carpenter, 2010; Floyd et al., 2000). Repeated evidence suggests that the aspects of PMT that address fear appeals the least (i.e., the coping appraisal pathway) are the most effective at influencing intention to change non-clinical behaviors such as physical activity and diet. Thus, it 
may be more appropriate to focus on self-efficacy related theory when attempting to promote PA and diet behaviors in a general population.

Social Cognitive Theory has been utilized in a number of studies aiming to positively impact PA and nutrition behaviors, with several of the more successful studies that were previously reviewed using a SCT framework to develop their intervention (LeCheminant \& Merrill, 2012; Morgan et al., 2011). Further, when studying other theories, the key component to SCT, selfefficacy, has consistently been found to be the construct most associated with behavioral intention and behavior itself when past behavior is not included (Floyd et al., 2000; Hagger, Chatzisarantis, \& Biddle, 2002). More specifically, PMT was revised to include the influence of self-efficacy in the mid-1980's, while TPB theorizes a construct called Perceived Behavioral Control, which shares a great deal of operational similarity to the construct of self-efficacy (Hagger et al., 2002; Rogers, 1983)

Social Cognitive Theory. In contrast to the health behavior theories that approach human behavior from a fear standpoint, Social Cognitive Theory (SCT; Bandura, 1991) suggests that the crux of change is in self-regulation and self-efficacy. The main component of SCT is selfefficacy, which is an individual's belief in their ability to accomplish a task in context-specific situations. Bandura (1991) suggests that humans engage in a process of self-regulation, which when combined with self-efficacy helps to dictate behavior. Self-regulation is divided into subprocesses, including self-monitoring, judgment, and self-reactive influences, all of which influence our motivation to engage in certain behaviors.

Self-monitoring helps provide individuals with the ability to understand the context that behaviors occur in, whether they were successful or not, and how one can change those behaviors in the future (Bandura, 1991). Without the ability to self-monitor, SCT posits that 
humans significantly diminish their ability to influence their motivation. A number of factors influence or distort one's ability to self-monitor accurately, including their values related to the behavior and mood states. For example, an individual who values the aesthetic changes that result from exercising is more likely to focus on the changes in their physique during an exercise program than other benefits (e.g., improved heart health, better mood, etc.). Self-monitoring also helps motivate individuals by providing them information with which they can set goals and evaluate their progress in relation to them.

Bandura (1991) suggests that the evaluation of a behavior is influenced by one's self-efficacy related to that behavior, and that self-efficacy is in turn impacted by the judgments made about the behavior. Judgment is influenced by personal standards of success, comparisons to others, how someone attributes the outcome of the behavior, and how much they value the activity. Those with higher self-efficacy are more likely to attribute success to themselves and failure to outside factors, and by meeting preconceived standards of success, humans are reinforced for engaging in a particular behavior. The impact of judgments that find significant discrepancy between that standard of success and the actual outcome are also largely determined by selfefficacy, as a large gap between current performance and a goal may be either motivating or discouraging depending on how much someone identifies with that behavior (Bandura, 1991).

One criticism that has been leveled against many of the health behavior theories (e.g., Theory of Reasoned Action, TPB, PMT) is that there is an inherent assumption that the same constructs that influence an individual's thoughts, intentions, and actions during adoption also facilitate maintenance of a particular behavior (Schwarzer, 2008). It has also been suggested that selfefficacy alone may not provide an effective bridge across the adoption-maintenance gap, in that belief in your ability to engage in a behavior may not be enough to sustain that behavior (Ryan, 
Patrick, Deci, \& Willams, 2008). In order to help individuals sustain health behaviors over a period of time, it has been suggested that a structured approach to maintenance needs to be adopted.

Self-Determination Theory. Self-Determination Theory (SDT) provides a framework for how and why people engage in specific behaviors, with the core assumption being that individuals who are intrinsically motivated are more likely to start and maintain a behavior (Ryan \& Deci, 2000). The theory suggests that there is a continuum that exists between amotivation and intrinsic motivation, and that the degree to which people are self-determined (i.e., intrinsically motivated) directly influences their adoption and maintenance of behaviors. The core principles of SDT are described as the basic human needs, that when fulfilled help us achieve a sense of well-being. These core principles are autonomy, competence, and relatedness, all of which build into an individual's sense of self-determination, or intrinsic motivation to engage in a particular behavior.

Autonomy can be described as the human drive to experience control over our environment, and can really be pared down to the experience of having choices or a say in what we do. With choice comes a desire to act in a way that is congruent with our own internal values. In worksite wellness settings, it has been suggested that many of the target behaviors are not inherently pleasurable activities, and that in order for individuals to be motivated to engage in these behaviors, they must find personal meaning or value in them (Ryan et al., 2008). When external regulations (e.g., pressure to conform to organizational norms, incentives, etc.) influence the degree of choice we have for a particular behavior, the intrinsic motivation to sustain these behaviors is often undermined by the desire to achieve external reward, avoid punishment, receive praise, or avoid disappointing those close to us. However, when an individual begins to 
identify with a certain behavior (i.e., "I'm an exerciser"), and these values are integrated into a larger schema (e.g., my health), individuals are likely to experience satisfaction in engaging in these behaviors, which in turn will help motivate further performance of the behavior (Ryan et al., 2008).

The second principle of SDT, competence, is closely related to self-efficacy, in that it suggests that people are attracted to and more likely to enjoy what they are good at. While SDT recognizes the similarity between the construct of competence and SCT's self-efficacy, the authors suggest that the interaction between autonomy and competence are critical in the development of intrinsic motivation and sustainable behavior change. The authors also highlight that by breaking down tasks and segmenting them into discrete sub-tasks, health promotion interventions can help foster feelings of competence quickly, which may build the momentum necessary for sustaining health behaviors (Ryan et al., 2008).

The third principle of SDT, relatedness, emphasizes the fact that human beings are by nature social, and suggests that the relationships that relate to a specific behavior will influence an individual's motivation to do that behavior. The relationship between participants in a worksite wellness program, and their feelings of relatedness to those who are also engaging, may help facilitate a sense of well-being that fosters intrinsic motivation for engaging in the program. Likewise, the rapport between a health professional and client can enhance an individual's experience of relatedness and may have positive impact on their intrinsic motivation related to that health behavior (Ryan et al., 2008).

Research using SDT as a theoretical framework in physical activity and diet settings has been limited, but has provided encouraging results related to the effectiveness of SDT in understanding these contexts. In one study, researchers looked at how receiving a brief SDT- 
based intervention compared to receiving a brief intervention paired with a three month long intensive counseling program geared towards developing intrinsic motivation for PA adoption (Fortier, Sweet, O’Sullivan, \& Williams, 2007). The experimental group received an additional six sessions with a physical activity counselor who aimed to increase participants' autonomy related to PA. More specifically, the intervention aimed to increase the perception that they had choices related to how they engaged in PA, and avoided putting external influence on their decisions (e.g., perceived guilt for not being particularly active). The experimental group ( $n=$ 61) was measured at baseline, six weeks, and again at 13 weeks in order to assess the impact of the intervention. When controlling for baseline variables, the experimental condition displayed a significant increase in autonomous motivation (partial $\eta^{2}=.04$ ) at six weeks, and a large increase in PA at 13 weeks (partial $\eta^{2}=.13$; Fortier et al., 2007). It is interesting to note that at six weeks and two counseling sessions, the experimental and control groups did not differ significantly in perceived competence. These results suggest that an intervention based on increasing participants' feelings of autonomy towards PA can lead to increases self-reported autonomous motivation and subsequent increases in PA behavior, despite a non-significant difference in perceived competence. This study also lends support to the assertion that adoption and maintenance of behaviors is affected by autonomy and competence, rather than just perceived competence alone (Ryan et al., 2008).

Another series of studies examined the relationship between SDT constructs and food regulation (Pelletier, Dion, Slovinec-D’Angelo, \& Reid, 2004). The authors surveyed 339 female students ( $M=22.5$ years old) using the Regulation of Eating Behaviors (REBS) scale to identify their eating-related motivation profile (i.e., amotivated, extrinsically motivated, intrinsically motivated). The responses on the REBS were then compared to the Healthy Eating 
Behavior Scale (HEBS), showing that participants who reported having intrinsic motivation for regulating their eating behaviors were more likely to report success in regulating their eating, and reported higher levels of concern as to the quality of the food they ate (Pelletier et al., 2004). Additional analyses, using the Self-Esteem Scale, and Life Satisfaction Scale, showed that intrinsic motivation was significantly correlated with self-esteem and life satisfaction in addition to healthy eating behaviors.

In a follow-up study, the same authors investigated the relationship between SDT constructs and eating behaviors in 111 participants who were at risk for developing CVD (Pelletier et al., 2004). Blood samples were drawn from the participants, and they were asked to complete the General Self-Determination Scale (GSDS), as well as a 24-hour dietary questionnaire and a three day food recall. The following week, participants received counseling from a dietitian as well as information on healthy eating, and were then given the REBS at a meeting in week 13 . At 26 weeks, the participants returned to complete an additional 24-hour dietary questionnaire and a three day food recall. On average, participants reduced their consumption of dietary fat by $12.4 \%$ and decreased saturated fat intake by $20.3 \%$ across the 26 week measurement (Pelletier et al., 2004). Using the REBS to categorize participants according to their degree of intrinsic motivation, the authors found that participants who reported being more self-determined were also more likely to persist in their efforts to lower their overall fat and saturated fat (Pelletier et al., 2004). These findings, coupled with findings from the previous study, suggest that SDT may provide a good framework through which dietary change can be understood and effective interventions can be built.

Social-Ecological Model of health promotion. While many of the theories that are applied to promoting health behavior specifically address the individual determinants of a 
person's actions, the Social-Ecological Model (SEM), as applied to health promotion, aims to better understand the interaction between an individual and his or her environment (Stokols, 1992). The argument for a more comprehensive model that includes the physical and social environment is that an individual's thoughts and actions do not exist in a vacuum, and that external influences play a role in shaping how people interact with themselves and with others.

In order to fully characterize the interaction between an individual and their environment, it is important to identify the components that influence the relationship. Environments can be seen in terms of their physical (e.g., lighting, proximity of workers) and social components (i.e., degree of communication between employees, attitudes towards health behaviors; Stokols, 1992). Likewise, participants of HPPs can be studied from a number of perspectives, including the individual, group, and organizational levels. Taking an ecological perspective also requires the acknowledgment that while HPPs usually occur in one context, health behaviors are either reinforced or discouraged across a variety of settings (i.e., home, work, school, etc.) and that ignoring these influences may reduce the effectiveness of HPPs.

Based on the wide variety of influences on an individual's behavior, SEM categorizes these influences based on their proximity to the individual and the scale on which they function. An individual's microsystem is defined as the people (i.e., family, friends, co-workers) and environments (i.e., home, work) that they interact with on a regular basis (Sallis \& Owen, 2002). The mesosystem consists of the interactions between components of the microsystem, addressing the fact that home, work, and social life all influence each other. Also included in the mesosystem are larger units of analysis, such as an individual's neighborhood. The model also recognizes larger systems that influence an individual's behavior, including mass media as well as the political and economic environment in which an individual lives, describing these as an 
individual's exosystem. Finally, under the title of the macrosystem, the model also takes into account the broad cultural beliefs and values that individuals are subtly and explicitly influenced by.

When applied to HPPs, SEM identifies a number of limitations related to programs that address individual level factors only. From a resource standpoint, impacting employee behavior on an individual scale is costly when compared to the potential to impact whole organizations through cultural or institutional interventions (Stokols, Pelletier, \& Fielding, 1996). Additionally, by taking an individual-level approach, interventions often fail to harness the interpersonal and institutional support that has the potential to reinforce individual-level change (Stokols et al., 1996). Stokols' (1996) guidelines on approaching HPPs with an ecological perspective suggest that interventionists look at the environmental aspects that are conducive to change, those that detract from employees' well-being, and identify the "leverage points" that allow for the greatest positive impact on the health behaviors of the individual and organization. To simplify the application of SEM to health promotion efforts, a framework was created that allows for better understanding of how interventions fit within an ecological perspective (Richard, Potvin, Kishcuk, Prlic, \& Green, 1996). The framework categorizes the setting of the intervention (e.g., small group, organization, community, society), and then defines the target of the intervention (e.g., individual, interpersonal factors, organizational factors, political factors) so that a clearer picture of how an intervention affects an array of behavioral determinants can be seen.

Some researchers have suggested that SEM also provides an effective framework for understanding participation rates in HPPs, identifying the intrapersonal (e.g., readiness to change, self-efficacy, previous history of participation), interpersonal (e.g., coworker support, 
social networks, personalized recruitment), and institutional (e.g., access to facilities, incentives, and visible support from management) factors that impact participation in HPPs (Linnan, Sorensen, Colditz, Klar, \& Emmons, 2001). To support these assertions, a qualitative evaluation of over 300 wellness coordinators, CFOs, and CEOs highlighted company culture as a significant factor in the success of HPPs (Berry, Mirabito, \& Baun, 2010). Additionally, several studies have utilized interventions that address individual, microsystem, and mesosystem determinants with great success (Blair, Piserchia, Wilbur, \& Crowder, 1986; LeCheminant \& Merrill, 2012; Sorensen et al., 1999). Additional details of the specific interventions will be elaborated on in the Clinical Effectiveness section of this review.

\section{The Financial Effectiveness of Health Promotion Programs}

Interest in the financial impact of HPPs has been an important topic of research for several decades. With the amount of money being spent on HPPs by insurance agencies and employers, and in light of ever-increasing health care premiums, it is critical to understand how these programs impact health care costs (Golaszewski, 2001; Phillips, 2009). The model that much of the economic research of HPPs relies on is that these programs will successfully reduce health risks in a specific population, and that this in turn will lead to reduced health care costs or increase productivity at work (Aldana, 2001). However, fully characterizing the relationship between HPPs and financial outcomes is difficult based on a number of factors.

Different programs target different health risks, and studies measuring the same health risks (e.g., tobacco cessation, BMI, etc.) often use different metrics in order to measure and classify participants according to risk status. The diverse evaluation methods make it difficult to generalize from one program to another (Nyce, Grossmeier, Anderson, Terry, \& Kelley, 2012). Authors often use different definitions of health care costs and financial impact. Some authors 
include only health claims (e.g., Milani \& Lavie, 2009) while others use inpatient costs, doctor's visits, and hospitalization days in their analyses (e.g., Fries, Harrington, Edwards, Kent, \& Richardson, 1994). To further complicate comparison from study to study, some researchers utilize self-reported financial information, others use claims data provided by insurance records, and others use a combination of both. Ideally, researchers would have access to a wealth of information, including but not limited to the cost of a) a person's health plan; b) sick leave; c) workers' compensation; and d) disability management, as well as the impact of absenteeism/presenteeism on productivity (Chapman, 2012).

Another methodological issue that arises when trying to understand the financial impact of HPPs is that most studies have a limited duration, which prevents long-term effects from being understood. Without following a cohort for a long period of time, it is difficult to know how HPPs alter long-term behaviors, and how risk factors are affected after the intervention(s) has been reduced or removed (Aldana, 2001).

Reviews of literature and meta-analyses. A review of 72 studies that directly measured an association or comparison between health risk factors and financial outcomes done in 2001 yielded strong support for the ability for HPPs to reduce health care costs (Aldana, 2001). Using research published between 1963 -2000, the author graded each study based on methodology, with the highest grades reserved for experimental/quasi-experimental designs. Although many of the studies reviewed differ in context, population, and design, there is still consistency across the results, showing that health promotion programs are associated with lower health care expenditure. Several of the more rigorous studies provided strong evidence for the causal nature of participation in health promotion programs and reduced health care costs as well. For the 13 studies that provided information on the cost-benefit ratios of HPPs, an average of $\$ 3.48$ of 
health care savings for every dollar spent on HPPs was calculated. This number rose to $\$ 4.30$ per dollar spent when the estimated impact of improving absenteeism was also taken into account. In this context, absenteeism is most often defined as the costs associated employees taking sick leave, and with lost productivity when workers aren't at work (Chapman, 2012)

When the relationship between specific health risks and healthcare costs were examined across a number of studies, the author found that there was a strong association between obesity, stress, having multiple risk factors, and increased healthcare costs. In a review of six studies examining the relationship between obesity and healthcare costs, Aldana (2001) found that five demonstrated an independent, strong association, between the two variables. Similar results were found for stress and healthcare costs, with all five studies that were reviewed demonstrating strong associations between increased stress and healthcare costs. Of the five studies that examined the impact of having multiple risk factors on health care costs, all five provided similar findings; additional health risks result in increases in healthcare costs.

Although 41 health risks were examined in total, looking at the data in aggregate did not allow for conclusions to be made for other risk factors (Aldana, 2001). One explanation for this lack of findings, particularly for health risks such as elevated cholesterol and hypertension, is that many risk factors do not manifest as diseases and elevated healthcare costs until later in life. Looking beyond the aggregate numbers for certain risk factors may also be important. For physical inactivity, three of the six studies reviewed showed a positive relationship between inactivity and healthcare costs, while three found no significant relationship, leading the author to conclude that more research was needed before a definitive statement could be made about the relationship. However, it was also highlighted that the more rigorous studies reviewed, which 
controlled for confounding variables and had large sample sizes, did find that physical inactivity is associated with increased healthcare costs.

In another review of the literature, 36 studies were reviewed that included research designs using comparison groups of nonparticipants in order to more accurately assess the impact of HPPs (Baicker, Cutler, \& Song, 2010). Most of the studies were done on employerbased HPPs, with most of the programs being implemented at large $(1000+$ employees $)$ companies. The review examined the characteristics of the HPPs in each study, finding that $80 \%$ of the studies used some form of HRA, while $40 \%$ of the studies used self-help materials (in the form of individual counseling or on-site group meetings). Additionally, financial incentives, in the form of bonuses or reimbursements, were used by $30 \%$ of the studies reviewed. Of the studies reviewed, $66 \%$ of the HPPs were aimed at improving fitness or weight loss, while $75 \%$ of the programs targeted multiple risk factors.

Baicker and colleagues (2010) examined 22 studies that measured health care costs. Of these 22 studies, 18 were previously reviewed by Aldana (2001), with the addition of four studies that had been published between 2000-2010. The return-on-investment (ROI) was calculated at $\$ 3.27$ saved for every dollar spent across the 22 studies examined. The average duration of these studies was three years, which is similar to Aldana's (2001) review, where the studies lasted 3.25 years on average. The ROI numbers varied when the studies were divided by research methodology. When only studies using random assignment or matched comparison designs, the ROI increased to $\$ 3.36$, while comparison studies that did not use these techniques reported an ROI of $\$ 2.38$. The authors point out that these numbers are low compared to other reviews (i.e., Aldana, 2001; Chapman, 2012), however they also suggest that this may be due to the more stringent inclusion criteria, as well as their method for calculating ROI (Baicker et al., 
2010). When identifying the mechanisms through which these savings are accrued, the authors suggest that ROI may be the result of a number of factors. These may include decreased replacement costs of workers who are absent, by making the workplace more attractive to other workers, reducing turnover at work, as well as improved health and reduced healthcare costs.

For most of the studies, data was not provided on how costs and savings changed from year to year. Without this information, it is difficult to know how to interpret the ROI numbers, particularly when first implementing a HPP. Additionally, the review looked at HPPs with a broad perspective, and did not go into detail as to which components may improve the ROI provided by HPPs, nor did it identify the specific health risks that may provide better ROI for HPP providers (Baicker et al., 2010).

These reviews can also be compared to an updated meta-evaluation conducted by Chapman (2012). Previous reports had been published by Chapman in 2003 and 2005, and the most recent update added a total of 6 studies, for a total of 62 peer-reviewed studies. The studies included in the meta-evaluation needed to have multicomponent programming (i.e., address at least three different health risks with the HPP being evaluated), be administered in the workplace, have a comparison or control group, and examine economic variables directly. Additionally, each study needed to have adequate statistical power. As compared with other reviews, the 62 studies analyzed in this evaluation had an average duration of 3.83 years. The author also notes that over half of the studies reviewed were published before 1996, and the overall findings suggest that more recent studies have more rigorous methods, use more advanced interventions, and are more likely to find higher cost-benefit ratios than older studies.

Looking at the 62 studies, health care utilization and health care cost were used as an economic outcome by $51.6 \%$ of the studies, while other studies used absenteeism, workers' 
compensation, or disability as outcome measures. Most studies (70.9\%) used only one outcome measure for their economic analysis, and it is suggested that this may result in understated costbenefit ratios (Chapman, 2012). Whereas the previous report provided a cost-benefit ratio of $\$ 5.81$ of savings for every dollar spent (using 22 reported studies; Chapman, 2005), the current meta-evaluation produced an average cost-benefit ratio of $\$ 5.56$ of savings for every dollar spent (using 25 studies; Chapman, 2012).

While there was overlap between some of the studies in each review, the inclusion criteria and methods for aggregating data for each was substantially different. Chapman (2012) suggests that because of the stringent inclusion criteria used by Baicker and colleagues (2010), and that they chose to limit their analysis to healthcare costs and the impact of absenteeism, it makes sense that their ROI was substantially lower than $\$ 5.56$. This fits with other authors' suggestions that without being able to accurately assess the full impact of HPPs, employers and insurers may undervalue and underinvest in their members' health (Nicholson et al., 2005). Despite the different outcome numbers provided in each of the three reviews, all of the authors suggested that improved rigor, for both individual studies and literature reviews, would serve the field of HPP well (Aldana, 2001; Baicker et al., 2010; Chapman, 2012)

Financial effectiveness of individual health promotion programs. The following HPPs have been broken down into categories based on their research design, according to the categories established in Golaszewski (2001); a) experimental/quasi-experimental; b) cohort studies; c) cross-sectional or descriptive studies. In addition, some of the programs reviewed here were highlighted by Golaszewski (2001) as "shining lights" which have helped push the understanding of the relationship between HPPs and financial outcomes forward. 
One of the earliest studies identified in his review examined the impact of a health promotion program implemented in the city of Birmingham during the late $1980 \mathrm{~s}$ in an effort to curtail rising healthcare costs (Harvey, Whitmer, Hilyer, \& Brown, 1993). At the time, healthcare costs had increased at more than twice the rate of national inflation in Birmingham, and the program, which was funded by the National Institutes of Health (NIH) consisted of a large, dedicated staff (e.g., nine full-time staff, including three exercise physiologists, three "health education interventionists" and a registered dietitian), medical screens every year that included biometric data (i.e., BMI, BP, cholesterol, triglycerides, etc.) and a self-reported HRA. Interventions were then offered that lasted 4-12 weeks, and were aimed at smoking cessation, weight reduction, hypertension control, and stress management. Lastly, the city opened a workout facility that was run by the three exercise physiologists and was open to all city employees.

To assess the financial impact of the intervention, the authors compared the actual medical expenses of city employees from 1985-1990 and compared them to the trends from the previous ten years. From 1975-1985, medical expenses per employee went from $\$ 692$ to $\$ 2,047$. For the following five years, these costs rose from $\$ 2,047$ to $\$ 2,075$. While this data lends support to the positive impact of the program, in order to evaluate the cost-effectiveness of the program, the authors compared the per employee difference between the city of Birmingham and the state of Alabama. In 1985, Birmingham employees cost $\$ 397$ more per employee than the state average. By 1987, this trend had been reversed, with Birmingham employees costing \$54 less, and by 1990 , this number had grown to $\$ 922$ less than the state average (Harvey et al., 1993). Overall, the authors calculated that the city of Birmingham saved $\$ 7,146,878$ from 19871990 , compared to the $\$ 2,000,000$ spent across the five years of the program. 
While these results were encouraging, it should be noted that no analysis was done to better understand the specific intervention components that produced the savings highlighted during the study. The authors also failed to account for the costs of incentives provided throughout the program, as well as other factors that may have affected the results of the study (i.e., a shift to HMO coverage during that time period; Golaszewski, 2001). However, the study does provide good evidence to support the cost effectiveness of a large-scale series of interventions implemented in a city setting.

Another study from the early 1990s used a yearlong randomized controlled trial to evaluate the impact of the "HealthTrac" HPP available to members of the Public Employees Retirement System of California (PERS; Fries et al., 1994). The program was geared towards reducing overall health risk through targeted interventions aimed to decrease behavioral and lifestyle risks (i.e., smoking, saturated fat intake). The study had 29,486 PERS members (employees and retirees) in the experimental group, and 1,487 controls who were randomized from the employee and retiree groups. The active participants in the experimental group returned health risk assessment at six or 12 months, had access to computer-generated reports that were individualized based on their responses to the HRA, and self-management and educational materials. Participants in the experimental group who did not return HRAs were classified as "passive" participants, and only received the self-management and educational materials.

Primary analyses consisted of comparing the changes in claims from a baseline year through the experimental 12-month period. The authors found that compared to the control group, the claims costs of the experimental group were approximately $\$ 3.2$ million less than would have been expected. It is important to note that when "catastrophic claims cost" (i.e., 
outliers who had costs of $\$ 50,000$ or greater) are included in the analysis, the savings theoretically grow to $\$ 8$ million. Additionally, the researchers found a significant difference in savings between active and passive participants that suggests that engagement in the HRA and individualized portions of the intervention had increased impact on claims costs. (Fries et al., 1993).

When interpreting these data, it is important to recognize that the authors only examined changes in claims up until the end of the intervention year, and that it is likely that the impact of the intervention might not be fully realized until a number of years later. Further, the intervention, which was mail-based, and provided educational and self-management tools at relatively low cost ( $\$ 30$ per person per year), was still able to demonstrate substantial savings (Fries et al., 1993).

Examining more contemporary HPPs provides similar results regarding the relationship between improving health risks and positive financial outcomes. The Highmark Employee Wellness Program was reviewed over a four year period, during which researchers matched wellness program participants with "risk-matched" nonparticipants in an effort to better understand how participation influenced healthcare costs (Naydeck, Pearson, Ozminkowski, Day \& Goetzel, 2008). Risk-matching, which was developed by the Mayo Clinic Division of Biostatistics, attempts to match participants and nonparticipants on variables that are associated with higher healthcare expenditures, and included age, gender, baseline medical expenditures, and evidence of chronic diseases (e.g., cardiovascular disease or diabetes). Once matching was complete, $t$-tests and $\chi^{2}$ were used to make sure there were not significant differences between groups prior to analysis. 
The Highmark wellness program included an HRA, online programming geared towards improving nutrition, weight management, and tobacco cessation, and on-site nutrition and stress classes. Six to 12 week campaigns were also periodically conducted to improve fitness and biometric screenings. It is important to note that Highmark had very high participation rates (9665 employees out of a possible 12,000 participated from 2002-2005) with $82 \%$ of employees also getting screenings done. This context is important when interpreting results, as company culture is an important factor in determining the impact of HPPs on both clinical and financial outcomes (Berry et al., 2010).

To perform the financial analysis, claims were extracted for both participants and the comparison group from baseline in 2001 to 2006, and outliers (claims greater than $\$ 100,000$ in a year) were excluded. Using a procedure that takes actual claims data over the study period, and then allows for growth curves to be generated, the authors were able to estimate the impact of participation, as well as identify how specific aspects of program participation impacted medical costs. The authors then estimated the annual savings, looking at overall, inpatient, outpatient, professional, and pharmacy payments across both groups. For participants, yearly savings came out to $\$ 176.47$ per person per year, with the largest difference being on inpatient expenditures (\$181.78 per person per year). Looking at participation specific results, the group that completed an HRA and used the fitness center saved \$151.36 per person per year when compared to nonparticipants, while the other comparisons were non-significant. Based on these numbers, and the cost of implementing the program, the authors calculated an ROI of $\$ 1.65$ for every dollar spent. While this ratio is below the ratios reported in the literature reviews described above, the authors of the current study suggest this is due to the expenses associated 
with operating and maintaining fitness centers, providing on-site health education classes, offering health coaching, and administering biometric screenings.

Another program that has undergone extensive economic analysis has been the "Live for Life" program sponsored by Johnson and Johnson (J\&J). First implemented in 1979, there have been several iterations of the program, and it has received a lot of attention from researchers interested in the relationship between HPPs and economic outcomes (Bly, Jones, \& Richardson, 1986; Henke, Goetzel, McHugh, \& Isaac, 2011). The first iteration of the Live for Life program, which was assessed from 1979 to 1983, consisted of a health screen, lifestyle seminar, and risk improvement programs (stress management, tobacco cessation, etc.), as well as altering the work environment to emphasize health. In order to assess the impact of the HPP on health care costs, medical care data was pulled from the J\&J self-insured medical plan. Researchers divided employees into an early exposure group $(n=5192)$, delayed treatment group $(n=3259$, and a control group that did not receive the intervention $(n=2955)$. Results, which were calculated using an ANCOVA as well as a least-squares regression, showed that the intervention groups experienced smaller increases in health care costs, hospital admissions, and days spent in the hospital compared to the nonintervention control group. In 1979 dollars, these savings equaled $\$ 980,316$, or $\$ 116$ per person throughout the intervention period.

To contrast this early effort to capture the impact of the Live for Life program, Henke and colleagues (2011) reviewed the updated version of the program, assessing the impact on healthcare costs from 2002-2008. The program shares some similarities with its predecessor, including healthy cafeteria choices and tobacco cessation programs. However, the program also offers on-site fitness centers, reimbursements for exercise expenditures, a pedometer program, health coaching, and online tools for weight management. Instead of using a RCT design to 
assess the financial effectiveness of the program, the authors compared J\&J outcomes to that of 16 other large companies (selected since they reflected the size and industry of J\&J). In their initial analysis, the authors used propensity-score matching to pair J\&J employees with "statistical twins" from control companies. The study then compared health risks and health care costs in order to understand the ROI of the Live for Life program. Costs were calculated by adding inpatient, outpatient, and pharmaceutical claims. Health risks that were considered were obesity, blood pressure, cholesterol, physical inactivity, poor nutrition (defined as $<5$ fruits/veggies a day), tobacco use, depression, and high stress.

The matched sample included 31,823 J\&J employees and an equal number of employees from comparison companies. Using multilevel growth curve modeling, the authors found that $\mathrm{J} \& \mathrm{~J}$ employees experienced a $3.7 \%$ lower average annual growth in medical costs when compared to their "twins", which resulted in \$535 per employee per year (in 2007 dollars). Using numbers from a previous review of literature that estimated average HPP costs at $\$ 144$ per employee per year, the authors calculated an ROI of \$3.92 saved for every dollar spent (Baicker et al., 2010; Henke et al., 2011). When using a more conservative program cost estimate of $\$ 300$, the ROI would be $\$ 1.88$ for every dollar spent. The authors do point out that one flaw in their study is that a number of the comparison companies also have HPPs available for their employees, which may mean that the savings may be greater than calculated. The two studies evaluating the Live for Life program provide a unique opportunity to see the evolution of a single HPP, as well as to see the improvements in study methodology and economic analysis. These trends fit with the suggestion of previous authors, who point out that recent studies have shown substantial increases in cost-benefit and ROI results, likely due to improved methods and analysis (Chapman, 2012). 
PepsiCo’s employee HPP, HealthRoads, has also received attention from researchers interested in the relationship between improving health risks and decreasing healthcare costs (Liu et al., 2013). A three-year evaluation was done of HealthRoads, from 2004-2007, that involved using an intent-to-treat approach in order to create distinct treatment and control groups. The authors also used the two years prior to the evaluation period as baseline data, and used this to control for regression to the mean effects. The program itself consisted of five different components; a) a self-administered HRA, b) case management, c) disease management, d) lifestyle management, and e) a nurse advice line. Eligibility for the various parts of the program was determined by a combination of HRA data, referrals, and claims data.

In order to assess the impact that the program had on healthcare costs, the authors compared medical costs from the second baseline year to each of the three subsequent years while controlling for individual health risk, as well as age, sex, and comorbidities. Based on the analyses, the authors concluded that eligible members had larger increases in costs per member per month during the first year, but by the end of the third year, had lower cost increases than the ineligible group. Looking at the cost breakdown more closely, the savings were generated by reductions in inpatient admissions and emergency room visits. The authors go on to point out that their analysis reflects other program evaluations, where costs increase during the first year, only to provide savings in subsequent years (Liu et al., 2013). However, the program evaluated consisted of disease management and lifestyle management programs, and as outlined in previous literature, disease management and health promotion may have different mechanisms for impacting economic costs.

Differing from other methodologies, a retrospective cohort design was used to evaluate the impact of Chrysler's StayWell Program on healthcare costs (Serxner, Gold, Grossmeier, \& 
Anderson, 2003). The evaluation period was from 1992-1997, and participants of the program were compared to nonparticipants over that time period. It is important to note that compared to previous methodologies, the current study design did not allow for randomization or matching of the treatment and control groups. This resulted in a participant group that was more likely to be female, and have medical claims when compared with the nonparticipant group. The StayWell program consisted of a HRA, which stratified members into risk categories, and targeted interventions or activities that were aimed at positively impacting health risk behaviors. More specifically, the interventions were geared towards raising awareness in participants, developing tools for behavior change, and reinforcing positive habits.

Data were collected for 26,411 participants, 49\% of whom completed an HRA, wellness activity, or both. Healthcare cost were totaled using inpatient, outpatient, and pharmaceutical costs, with outliers $(>\$ 100,000$ in claims) were truncated at $\$ 100,000$ for the analysis. General linear modeling was used to control for differences in demographic information and baseline medical costs. Based on the claims data collected in 1997, HRA participants averaged \$212 less than non-participants. Looking across the full study period, those who completed HRAs more often increased their cost savings. More specifically, completing one HRA was associated with \$83 in savings, two HRAs represented an average savings of $\$ 173$, and participants who completed three or more HRAs produced an average savings of $\$ 543$. When subsequent analyses assessed the impact of completing HRAs and engaging in wellness activities, the savings increased as well, moving to $\$ 344, \$ 391, \$ 607$, and $\$ 625$ for the groups who completed 0, 1, 2, and 3+ HRAs respectively (Serxner et al., 2003). Despite a less rigorous methodology, the evaluation of the StayWell program provides insight into a potential dose-response 
relationship between participation in HRAs and/or wellness programming and healthcare savings.

While most of the research that has investigated the impact of HPPs on healthcare costs has been focused on employer-driven wellness efforts, one study provided an economic analysis of A Healthier You (AHY), a program offered by Blue Cross Blue Shield of Kansas City (Hochart \& Lang, 2011). The AHY program is unique because it was implemented through the insurance company and the analysis included 15 different employer groups from various industries. The AHY program itself consists of a worksite assessment that evaluates the health culture, leadership support, and resources of each workplace, and is followed with biometric screenings and HRAs of employees. Employees review their screening results with a health care professional, and are then referred to different resources (e.g., telephone coaching, worksite/webinar education classes, online behavior change tools, referrals to care management programs, etc.). Employers also receive aggregate scores of both the screenings and HRAs as feedback, and a 12-month plan is created geared at improving the culture and specific health risks of each worksite.

In order to evaluate the impact of AHY on healthcare costs, the study looked at the different employer groups across a three-year period, from 2006-2008. Healthcare costs included emergency room visits, inpatient admissions, and overall medical costs based on claims data. Claims data for the 15 employer groups were then compared to 7 employer groups for whom more than 100 employees did not participate in AHY. Compared to the non-AHY group, employees from the AHY group had significantly lower increases in emergency room costs per employee per month across the three-year study period (15.3\% increase compared to a $62.2 \%$ increase), and demonstrated significantly slower growth in overall medical costs $(0.9 \%$ 
compared to $21.7 \%$ ) over the study period (Hochart \& Lang, 2011). The authors do point out that the results may be skewed, based on the fact that the majority of the members who participated in the AHY programming were low risk (70.4\%). There was also a lack of standardization across the employer groups in how the program was delivered, which makes the results difficult to interpret. However, the study does provide an important view into insurerbased wellness programming.

\section{The Clinical Effectiveness of Health Promotion Programs}

The research done assessing the clinical effectiveness of HPPs is diverse. While the broad goal of HPPs is to improve employee health, the definition of health, and the interventions built to positively impact health vary greatly. Further, despite sharing the worksite as the point of implementation, the HPPs reviewed in this text also differ in their target population, desired outcomes, and the methodology behind how outcomes are evaluated. Some programs use objective measures of health (e.g., blood pressure, cholesterol, heart rate variability, or weight) while other programs utilize subjective measures (e.g., stage of readiness, self-reported food intake, days and minutes spent exercising), making it difficult to make generalizable statements about the nature of HPPs and their impact on health. However, one promising trend has been an increase in sophistication of both the interventions themselves, as well as the methodologies developed to study them.

Early health promotion programs. The Johnson \& Johnson "Live for Life" program was one of the earliest and most rigorously tested HPPs. The first version of the program, developed in 1979, aimed at improving overall health, as well as health care utilization and cost (Blair et al., 1986; Bly, et al., 1986). The researchers used a combination of $\mathrm{VO}_{2 \max }$, estimated from a submaximal bicycle test, a global self-report measure of physical activity (i.e., "compared 
to others your age, do you consider yourself extremely inactive, extremely active, or somewhere in between?"; Blair et al., 1986), a specific question about participating in vigorous exercise (i.e., jogging 16 kilometers $(\mathrm{km})$ or more a week, biking at least $80 \mathrm{~km}$ a week, playing racket sports for five hours or more a week), and a seven day physical activity recall. The authors suggested that by assessing PA in a multitude of ways, a more accurate estimate of actual behavior could be obtained. Using a general linear model technique, the authors compared the experimental group $(n=2,600)$, which had received both an HRA and the Live for Life intervention, to an HRA only control group $(n=1,700)$. When adjusted for age, sex, and other baseline values, the experimental group reported themselves as more active at the end of both years of the program, and reported increased total output and output in hard activity when compared to the control group. Additionally, in the experimental group, roughly $20 \%$ of the women and $30 \%$ of the men reported engaging in vigorous exercise during the two-year study period, compared to $7 \%$ and $19 \%$ respectively in the HRA-only control group. Finally, in the experimental group, $\mathrm{VO}_{2 \max }$ increased $8.4 \%$ above baseline in year one, and $10.5 \%$ above baseline in year two, compared to $1.5 \%$ and $4.7 \%$ respectively for the control group.

Additional analyses looked at the changes in physical fitness and exercise results and their relationship to additional risk factors measured on the HRA. Changes in $\mathrm{VO}_{2 \max }$ were significantly related to changes in coronary heart disease, decreases in body weight and body fat, and a decrease in Systolic BP. For participants who reported the largest increases in energy expenditure over the two year period, there was also a significant increase found in their selfreported well-being, depressive symptoms, and health attitudes (Blair et al., 1986). This early assessment provided good evidence that health screenings and a physical activity intervention 
could have significant positive impact on PA behaviors, objective measures of health, and psychosocial variables (Blair et al., 1986).

Researchers examining the impact of the Healthtrac program described in the previous section used a different method to conceptualize changes in participants' health status. Researchers used self-report data related to health behaviors and risk factors gathered from the HRA (e.g., smoking, fat intake) and created a summary "health habit risk score" to aggregate participants' overall health (Fries et al., 1994). The authors then looked at the differences between the experimental and control groups at 6,12 , and 18 months. Over the 18 months that the participants were studied, BMI changed very little, however there were significant decreases in dietary and saturated fat intake, as well as moderate increases in exercise minutes (the specific results were not reported). Additionally, the risk score aggregate decreased for all participants in the experimental group, with between 6-12\% improvements across 18 months, providing early support for the impact of HPPs on overall health (Fries et al., 1994).

Reviews and meta-analyses. Building off researchers' early work evaluating HPPs, there has been a great deal of research done. Several meta-analyses have recently been conducted that provide a broad perspective on the impact that HPPs can have on different health outcomes, behaviors, and psychosocial variables. Hutchinson and Wilson (2011) reviewed 31 studies spanning 1999-2009 with the goal of identifying the theoretical frameworks and program components that had the strongest impact on nutrition and PA outcomes. The theoretical categories used were adapted from Sussman and colleagues (2006), and included education, social influence, cognitive-behavioral, motivation enhancement, and exercise. It is useful to point out that despite the wealth of research in the area of HPPs, a minority of studies focus on the theoretical constructs that dictate how behavior is changed, and the behavior change 
processes themselves. The authors' focus on categorizing interventions theoretically in this meta-analysis helps provide important information that begins to illuminate how these programs might work.

Effect sizes were calculated using Cohen's $d$ for the impact of reviewed interventions on measures including fruit, vegetable and fat intake, PA behaviors and fitness, weight, cholesterol, heart rate, blood glucose, and blood pressure. The effect sizes were then grouped according to outcome measure and theoretical category, and an average effect size was calculated. Studies were only included in the review if they had a control group, although not all studies had randomization of the groups. Of the 31 studies, 21 reported post-intervention data on the differences between experimental and control groups, while 10 included pre-intervention and post-intervention data, allowing for "change-over-time" calculations.

Looking specifically at the change-over-time studies, large effect sizes were found for motivation enhancement interventions $(d=1.98)$ and a small significant effect was found for interventions based on exercise alone $(d=0.33)$. The authors point out that these effect sizes were not consistent with the overall results from the post-intervention studies, which found small effect sizes for each theoretical category. This may be due to the nature of the analysis, which combined the effect sizes for numerous outcome measures, rather than accurately representing the intervention effects (Hutchinson \& Wilson, 2011). More specific analyses looked at the effect sizes across theoretical category and outcome measure, providing a more in-depth look at the nature of the interventions. For the change-over-time data, there was a moderate effect found on cholesterol when using educational interventions $(d=0.69)$, and small effect sizes across most of the outcome variables in the social influence, education, and motivation enhancement categories. 
Taken together, these results help highlight a few important trends related to HPPs. First, while most of the theoretical approaches yielded at least small effect sizes, the aggregate effect size for motivation enhancement strategies (e.g., strategies that enable participants to clarify their reasons for change, strategies that may move participants through the stages of change, or strategies that used incentives to reinforce successful behavior change) suggest that these strategies are effective in producing positive change across a wide number of program objectives and outcome measures. Second, the range effect sizes produced when analyses looked at specific theoretical categories and outcome measures provides evidence for the necessity of matching intervention strategies to the specific health outcome of interest (Hutchinson \& Wilson, 2011). It is important for interventionists to be aware of these differences when developing HPPs.

A separate meta-analysis, conducted by Rongen and colleagues (2013), took a different approach to summarizing the HPP literature. Whereas the previous analysis looked at effectiveness across intervention type and outcome measure, the authors of this study chose to focus on the impact that the target population, intervention characteristics (e.g., number of contacts during intervention period), and methodological quality had on the effectiveness of HPPs (Rongen, Robroek, van Lenthe, \& Burdorf, 2013). The meta-analysis was comprised of 21 different RCT interventions, published between 1993 and 2012, and aimed at improving health outcomes (e.g., physical activity, nutrition, obesity, self-perceived health, smoking cessation, absenteeism, and work productivity). Methodological quality was based on a checklist developed by previous authors, and allowed for a grade between 0 (poor), and 9 (excellent; Verweij, Coffeng, van Mechelen, \& Proper, 2011). 
Without stratifying by outcome measure, a pooled effect was calculated for the HPPs, with a significant generic effect size of 0.24 . When split out by outcome, similar effects were found on measures of sickness absence $(\mathrm{ES}=0.21)$, productivity at work $(\mathrm{ES}=0.29)$ selfperceived health $(E S=0.23)$, and work ability $(E S=0.23$; Rongen et al., 2013). Looking specifically at methodological quality, effect sizes for studies graded as poor were nearly triple that of those with good or excellent methodology $(\mathrm{ES}=0.41$ compared to $\mathrm{ES}=0.14)$, and studies classified as having low participation $(<34 \%)$ yielded effect sizes that were 3.8 times greater than studies with higher participation. It was theorized that this result may have been to self-selection in studies with lower participation rates, with more motivated participants persisting with the interventions (Rongen et al., 2013).

The authors also found small effect sizes when the study population was younger $(\leq 40$ years old; $\mathrm{ES}=0.13)$, and predominantly white collar $(\geq 67 \%, \mathrm{ES}=0.33)$, however when the analyses controlled for the methodological quality of the studies, these results were nonsignificant (Rongen et al., 20113). The effect sizes are comparable to the small effect sizes found for many of the theoretical categories investigated by Hutchinson and Wilson (2011), and may speak to both the difficulty of changing behavior as well as the importance of rigorous study methodology. For interventionists, one of the most useful results reported was that interventions that maintained weekly contact with their participants were nearly four times more effective when compared to those who were not. This specific result may help inform future HPP design.

Looking at physical activity specifically, one meta-analysis addressed the effectiveness of HPPs on improving PA behaviors, work-related outcomes, health, and well-being (Conn, Hafdahl, Cooper, Brown, \& Lusk, 2009). Including over 138 published and unpublished reports spanning from 1969-2007, the authors coded for workplace and intervention characteristics as 
well as intervention effectiveness. The resulting data suggested that most interventions were geared towards individual-level change, with $80 \%$ of the studies including motivational or educational techniques. Extrapolating from the overall effect size of the studies included $(d=$ 0.21 for PA behavior), the authors suggest that the interventions improved PA behavior by roughly 612 steps/day, while overall fitness had a larger effect size $(d=0.47-0.57$ depending on methodology). The authors also reported on specific characteristics that resulted in improved effectiveness of HPPs. More specifically, larger effects were reported for programs that had employees exercise on paid company time, as well as employees who helped design and implement the interventions (Conn et al., 2009).

While previous reviews addressed broad ranging HPPs or PA specific interventions, one systematic review investigated diet interventions specifically (Mhurchu, Aston, \& Jebb, 2010). The objective of the review was to get a better understanding of how HPPs can impact employees' diets. The outcomes of interest included total energy consumption as well as fruit, vegetable, and fat intake. To measure these outcomes, self-report data were often used (e.g., seven-day food recall, or food frequency questionnaires), although three studies made use of cafeteria sales data for a more objective measure of changing nutrition behaviors. Sixteen studies were included in the review, with 10 RCTs, five studies that only had pre- and postintervention data, and one quasi-experimental design. One of the strengths of this review was that it included studies from North America ( 9 of the 16 studies), Europe (6 of the 16 studies), and one study with an international intervention. Looking at the theoretical approach of the studies included, half were educationally based, six aimed to make environmental change as well as use educational materials, and two attempted to impact worksite culture or policy, with the 
specific strategies to prompt change varying greatly (e.g., computer-tailored feedback, weekly email messages, one-to-one counseling, shopping tours).

The results of the review help emphasize the complexity of changing nutrition behaviors. Most of the studies recorded small changes in fruit and vegetable intake, as well as total fat consumed. The largest reduction in fat intake was a moderate $9 \%$ (de Bourdeauhuij, Stevens, Vandelanotte, \& Brug, 2007), with the most effective fruit and vegetable study improving the number of servings consumed by participants by $16 \%$ (Sorensen et al., 1999). The few studies that did report on the impact of the intervention on weight and BMI found equivocal results, with two reporting limited impact on weight, and the third reporting an increase in BMI for the experimental group.

The review by Mhurchu and colleagues (2010) gives a broader perspective into the nature of changing dietary behaviors, in particular the difficulty in making significant change. When the data from the three review studies are looked at as a whole, it is clear that HPPs aim to accomplish the difficult goal of changing complex and ingrained behaviors. These reviews also illustrate the complicated interaction of factors that impact intervention effectiveness, including participant characteristics, target outcomes, theoretical approach, and intervention components. Overall, the most effective HPPs were resource and time intensive, and individualized/tailored to meet participant's specific needs (Pelletier, 2011; Rongen et al., 2013; Sorensen, Linnan, \& Hunt, 2004).

Contemporary health promotion programs. As the field of health promotion has progressed, researchers have taken advantage of evolving technology to help positively impact health behaviors. Researchers have begun using a combination of e-mail contact, internet-based resources, and computer-tailored feedback to help reach participants and facilitate change. One 
recent intervention used computer-tailored advice related to self-reported PA behaviors, as well as fruit and vegetable intake, and provided feedback related to perceived barriers and how participants might better meet health guidelines (Robroek, Polinder, Bredt, \& Burdorf, 2012). As part of the web-based intervention, participants were also prompted to self-monitor their fruit and vegetable intake, PA behavior, and weight. Researchers randomized participants into either an experimental $(n=465)$ and control $(n=459)$ group. Participants were assessed at baseline, at 12 months, and again at 24 months, and were asked to complete the International Physical Activity Questionnaire (IPAQ), the Dutch Food Frequency Questionnaire, and measures of selfefficacy, perceived barriers, and intention to change their behavior. Using multi-level logistic regression analyses, with age, sex and baseline responses, the authors found no significant effects of the intervention on measured outcomes. However, when participants were categorized based on whether or not they met guidelines prior to participation, the intervention was found to have a positive effect on meeting fruit intake guidelines for those who were not previously successful in doing so $(\mathrm{OR}=2.03$; Robroek et al., 2012).

The authors point out that a high number of participants were already meeting guidelines for PA (68\% with at least 30 minutes of activity most, if not all days of the week) fruit (54\%) and vegetable (45\%) intake prior to beginning the intervention, and that this may have had some effect on the results. However, there are several aspects of the intervention that may have produced limited study findings as well. The authors point out that the intervention lacked structure, as participants were encouraged to visit the website, and were only prompted once a month with e-mail reminders. This may have decreased the effectiveness of the intervention, as increased contact and direction have been found to improve the impact of HPPs (Rongen et al., 2013). Additionally, the study lacked an environmental component, addressing behavior change 
at the individual level only, which may have reduced the impact of the intervention (Robroek et al., 2012).

Using a contrasting approach, the WellSteps wellness program implemented a two year long HPP for a small US company $(n=267)$ using a HRA, a combination of e-mail and print media, and in-person campaigns to help impact health behaviors (LeCheminant \& Merrill, 2012). A consultant also worked with the on-site wellness coordinator to tailor the messaging to fit the company culture and to begin enacting organization-level change. The consultants used the CDC community guide's "checklists for change" to inform their environmental evaluation and subsequent 3-year wellness plan development. In conjunction with the effort to change the company wellness culture, six campaigns were offered once during each year of the two-year program, and were aimed at changing eating, exercise, and sleep habits, as well as working towards decreasing employee stress. The campaigns were designed using Social Cognitive Theory (SCT) and the Transtheoretical Model (TTM) as their theoretical foundations, and emphasized improving self-efficacy and behavioral capability for the targeted behaviors. Campaigns were set up so that employees would have discrete weekly tasks to accomplish throughout the duration of the campaign, support materials and resources (e.g., pedometers) were provided during the appropriate campaigns, and employees who completed a HRA and at least one campaign a year were entered into a drawing to win a small prize at the end of the year.

The HRA was offered to all employees, with $86 \%$ of employees completing the assessment at baseline, $64 \%$ at one year, and $65 \%$ at two years. Of those who completed a HRA, $80 \%$ also completed at least one campaign during the year. For the subsample of employees who completed a HRA at each time point ( $n=116,43 \%$ of the company), there were significant changes in a number of health outcomes. Employees increased their exercise frequency from 2.5 
days/week to 3.2 days/week at the end of year one, and increased their duration from 120.5 minutes/week to 198.4 minutes/week, with the frequency and duration holding steady through the second year. Additionally, there was a significant increase in the number of employees meeting the CDC guidelines for fruit and vegetable intake, with $22 \%$ meeting the guidelines at baseline, $41 \%$ at year one, and $49 \%$ at the end of year two. (LeCheminant $\&$ Merrill, 2012).

The WellSteps program contrasts from the previous intervention in a number of ways. First, the campaign components were developed using a theoretical framework, and were structured in a way that provided weekly tasks that built on previous weeks. The campaigns were also offered twice throughout the study period, and there were a variety of health-related topics addressed by the campaigns (LeCheminant \& Merrill, 2012). The use of e-mail reminders, posters, and postcards, which were tailored to employee's responses to TTM questions on the HRA may have added to the effectiveness of the program as well. Finally, unlike the exclusively web-based program developed by Robroek and colleagues (2012) the WellSteps program attempted to change company-wide culture, which may have also facilitated and reinforced individual's behavior change.

While many of the meta-analyses and individual studies choose to address multiple health behaviors at a time, there are also a number of interventions created to address dietary behaviors specifically. One of the most successful programs highlighted in Mhurchu and colleagues (2010) review of dietary interventions was the Treatwell 5-a-day program (Sorensen et al., 1999). The program utilized SEM in an effort to address not only individual-level change, but also microlevel change at the worksite and within the family. The intervention had two different arms, offered at 22 different sites for a period of 19.5 months; one in which the worksite was the primary intervention site, and another that addressed both work and home environments. 
Outcomes for these groups were compared to a control group, which received a minimal amount of resources (i.e., exposure to the 5-a-day media campaign, a one hour presentation on nutrition, and access to a cancer information hotline).

For the worksite-only intervention arm, employees were recruited to help plan and implement the program using "employee advisory boards", and had significant impact in creating the intervention for their specific worksites. The intervention itself included a kickoff festival to develop awareness of the program, ten 30-minute discussions that were used to educate employees, and an education campaign that lasted 3-5 weeks each year of the program. In addition to these events, worksites were encouraged to offer increased numbers of fruit and vegetable options at their cafeterias, and introduced point-of-choice labeling of fruits and vegetables to help facilitate increased intake. For second arm of the intervention, individuals received the worksite intervention, as materials and family specific content. A 5-part workbook was sent home with each employee, who received feedback on his or her responses upon returning it to the researchers. Employees also received a family-based newsletter, had a family festival, and received educational materials in the mail (Sorensen et al., 1999).

From the worksites, employees were randomly selected at both baseline $(n=1359)$ and follow-up (at the end of the intervention; $n=1306$ ), with $47 \%$ overlap from baseline to followup in respondents. The respondents were predominantly female (84\%) and most had post-high school training $(80 \%)$. Respondents were asked to complete a food frequency questionnaire as well as a six-question measure for both perceived coworker and household support for their dietary change. Using mixed-effects linear modeling to take into account the nested nature of the intervention, the authors reported no change on household support, but a significant increase in perceived coworker support at the end of the intervention. Despite perceptions of support, the 
worksite-only intervention group reported a 7\% increase in fruit and vegetable consumption (equivalent to a 0.2 serving/day increase), while respondents from the combined intervention reported a $19 \%$ increase (equivalent to a 0.5 serving/day increase; Sorensen, 1999).

The Treatwell 5-a-day program compared favorably to earlier dietary interventions, which reported increases between 0.16-0.19 servings/day. In Mhurchu and colleagues (2010) review, the Treatwell program was one of two studies that included an environmental component to the intervention. Much like the WellSteps program, the current intervention engaged employees in the process of developing and implementing the intervention, and also tasked them with helping to shift the environment and culture of workplace to help facilitate change (LeCheminant \& Merrill, 2012; Sorensen et al., 1999)

In another program geared towards facilitating dietary changes in employees, 110 employees of an aluminum manufacturing company were included in an evaluation of the Preventing Obesity Without Eating like a Rabbit (POWER) program over a three-month period. The participants were recruited from blue-collar shift working crews, and randomized to the experimental $(n=65)$ or control $(n=45)$ groups. On average, participants were obese $(M=30.5$ BMI $)$ and middle aged $(M=44.4$ years old; Morgan et al., 2011). The POWER program consisted of a three-month long intervention that was based on constructs from SCT (e.g., outcome expectations, behavioral capability, self-monitoring and self-efficacy). The program began with one 75-minute education session, at which point participants were given a handbook outlining the program as whole, and access to a website (calorieking.com.au) that would allow them to enter their weight, food, and exercise. The participants were also given a website user guide, and asked to record their weight daily, and document their food/PA behaviors for the first four weeks, half of the second month, and one week in the third month. Based on the dietary 
information entered, the researchers provided individualized feedback and recommendations via e-mail up to seven different times throughout the three months. In addition to the one in-person contact and Internet access, the experimental group received a pedometer to track their steps, and the crew that had the highest average weight loss at the end of the three month program was given a prize (Morgan et al., 2011).

The primary outcome that the POWER program targeted was weight, with secondary outcomes including objective health measures (i.e., blood pressure and resting heart rate) as well as behavioral outcomes (PA and dietary behaviors, as well as workplace productivity). To assess the impact of the intervention, the authors used a mixed model that included dropouts' data to allow for an intention-to-treat analysis, with age and SES used as covariates. Tests of the baseline groups found no significant differences, however at the end of three months there was a significant weight loss effect for the experimental group $(M=4.3 \mathrm{~kg}$ of weight loss, $p<.0001, d$ $=0.34$ ). The authors also looked at the nature of the online component of the program, finding that only $28 \%$ of the experimental group complied with the online component, but also finding a significant difference in weight loss between those who did utilize the web-based resource $(M=$ $8.0 \mathrm{~kg}$ lost) compared to those who did not $(M=2.0 \mathrm{~kg}$ lost $)$. The authors also reported significant correlations between the number of daily diet entries and weight change $(r=0.42, p$ $<.04)$, and weekly weight entries $(r=0.52, p=0.1)$. For secondary outcomes, the POWER program had moderate, significant effects on a number of measures, ranging from an average difference in waist circumference of $5.9 \mathrm{~cm}(d=0.41)$ to a lowering of resting heart rate by an average of 7.9 beats per minute $(d=0.81)$. The authors also found a significant effect on mental health scores $(d=0.74)$, and reported absenteeism $(d=0.72$; Morgan et al., 2012). 
The results of the POWER studies are encouraging, and provide useful contrast to previously reviewed research, which has used similar Internet-based self-monitoring techniques. The current study provided additional support materials, in the form of a user's guide and program handbook, which helped participants navigate the web program and outlined specific expectations regarding how often participants should record their weight and health behaviors. The intervention was also developed using SCT constructs, which allowed the authors to clearly identify the purpose of each intervention component, the associated theoretical construct, and the proposed mechanism of behavior change, which may have added to the efficacy of the program. It is important to note however that there was a small sample for the program evaluation, and while the weight loss over three months was large, additional research needs to be done to replicate these results.

While most HPP programs focus on a combination of PA and dietary behaviors, there are some studies that choose instead to focus on stress reduction or management as an avenue for improved employee health. Consistently elevated cortisol levels are associated with a wide array of subsequent issues, including elevated BG, BP, waist circumference, triglycerides, etc. (Chandola, Brunner, \& Marmot, 2006). In an effort to identify which stress-reduction techniques were most effective in reducing perceived stress, sleep quality, and self-reported depression, Wolever et al. (2012) developed a three arm RCT that included a yoga intervention, a mindfulness intervention, and a control group. Participants were 239 employees who volunteered for the study. On average, the participants were mostly female (86.6\%), had some form of post-high school degree, income between $\$ 100,000$ and $\$ 150,000$, and had an average age of 42.9 years old. In order to meet inclusion criteria for the study, participants had to score 
higher than a 16 on the Perceived Stress Scale and could not have had previous experience with either yoga or meditation.

The yoga intervention consisted of 12 one-hour classes across three months, during which participants were lead through guided relaxation, yoga postures, breathing techniques, and were provided tips for practicing at home. The authors suggested that the combination of breathing techniques and physical postures would positively impact autonomic nervous system activation as well as physiological stress. In comparison, the "Mindfulness at Work" intervention also had 12 one-hour classes, with an additional two-hour "intensive class" at week 10. The program taught mindfulness principles that were aimed at reducing work-related stress, facilitating work-life balance, and engaging in active self-care. Participants also received handouts for both their home and office to help them remember and practice these techniques. Participants in this intervention were either provided the information during in-person sessions, or via an online classroom designed to allow for two-way interaction during the class (Wolever et al., 2012). The participants varied significantly at baseline in reported race, ethnicity, and income, all of which were used as covariates during data analysis. The authors used a combination of ANCOVA and MANCOVAs to determine the impact of the interventions on a number of outcome measures, including self-reported stress, sleep quality, productivity, blood pressure, and heart rate variance (HRV; i.e., heart rate coherence). Coherence describes a situation when your heart is beating in a pattern consistent with blood pressure, respiration, and other bodily rhythms, which in turn reduces heart rate variability (HRV). Increased HRV has been connected to increased psychological and physiological status, as well as being related to overall health risks (Bedell \& Kaskin-Bettag, 2010). 
Based on the data analysis, the mindfulness group differed significantly from the control group, reporting decreased perceived stress $\left(\eta^{2}=.13\right)$ and decreased sleeping difficulty $\left(\eta^{2}=\right.$ $.04)$. While the yoga intervention also reported decreased stress $\left(\eta^{2}=.06\right)$ and difficulty sleeping $\left(\eta^{2}=.04\right)$, there were no significant differences when the two interventions were compared to each other on the PSS or sleep quality scales. On the measure of HRV, both groups improved heart rate coherence, with the mindfulness group $\left(\eta^{2}=.03\right)$ and yoga group $\left(\eta^{2}=.18\right)$ both displaying significant differences when compared to controls. Follow-up analyses were done comparing the in-person and online mindfulness cohorts, finding that the online participants displayed a significant improvement in $\operatorname{HRV}\left(\eta^{2}=.04\right)$ when compared to the in-person group. The authors suggest that this may be due to the attrition rates of the in-person mindfulness group, which had twelve dropouts compared to the online component's two.

The current study provides useful insight into developing effective stress reduction programs. First, it found both the yoga and mindfulness interventions to be relatively comparable in their impact on perceived stress, sleep quality, and improved heart rate coherence. Additional research is needed to determine whether or not matching employees based on their disposition (i.e., higher trait mindfulness) or preference would improve the effectiveness of these interventions. It is also promising to see results that support the efficacy of online stress reduction techniques. In-person interventions require a significant amount of time and resources, and by utilizing technology to help provide the "Mindfulness at Work" program, some of these drawbacks may be minimized.

One unique study of stress reduction used biofeedback to help participants regulate HRV and decrease perceived stress (Bedell \& Kaszkin-Bettag, 2010). For the study, 149 participants were given a coherence feedback monitor and taught self-regulation techniques using the 
HeartMath program, and these participants were compared to 164 participants who received a phone-based lifestyle modification program instead. The HeartMath program uses the emWave PSR to provide feedback on HRV in real time while participants practiced self-regulation skills. To help develop these skills a six-week period, participants had six 30-45 minute sessions with a HeartMath coach, during which they learned and practiced stress-reduction techniques using the feedback device.

As part of their insurance plan, participants had previously completed a HRA, which included measures from the Stress and Well-Being Survey (SWS). Using a single-factor ANOVA to compare the experimental group to the phone-coaching group, the researchers found significant differences in self-reported total stress, well-being, work stress, physical symptoms, and stress management ( $p<.05$; Bedell \& Kaszkin-Bettag, 2010). These results suggest that even over as short a period as six weeks, positive impact can be made on a number of selfreported outcomes, however the current study did not address long-term and objective measures of health (i.e., blood pressure, weight, etc.) and more research will need to be done to assess the overall effectiveness of these types of interventions.

Increasing participation in health promotion programs. Previous research looking at HPPs has resulted in authors concluding that there is likely a dose-response relationship between the program engagement and changes in health behaviors (Erfurt, Foote, \& Heirich, 1991; Serxner et al., 2003). The prevailing attitude is that if employees don't show up to HPPs, and are not engaged, it is impossible to reap the benefits of the HPP. In an effort to improve participation and engagement in HPPs, programs have implemented different strategies to help decrease the barriers to participating in HPPs and to increase the benefits of engaging in wellness 
programs. Two of these strategies are using computer and web-based interventions, and the use of incentives to encourage employees to participate in HPPs.

The impact of technology on health promotion programs. One of the difficult aspects of creating HPP interventions that are effective, and at the same time capable of reaching a broad population, is that many interventions are resource intensive. Many of the previously reviewed programs have multiple in-person counseling or dietary meetings, on-site fitness facilities at which participants were asked to work out, or large amounts of paper-based resources that need to be disseminated. With the technological improvements seen over the last $20+$ years, one alternative to the resource-heavy, in-person HPP model is to utilize the computer and internet to deliver content and connect participants with professionals. However, with a change in modality, it is important to determine whether or not computer- and web-based interventions are effective in making impact on employees' health behaviors.

Research has started to emerge that looks at the differences between technology-based and traditional interventions, with some promising findings. In a comparison of 17 studies that assess the impact of both web-based and non-web-based interventions on a number of variables (e.g., increased exercise time, knowledge of nutritional status, increased participation in healthcare), the authors showed that 16 of the studies provided positive effect sizes for the webbased intervention (across all studies, the Hedges $d=.01-.75$ ) with only one of the studies reporting a positive effect size for the non-web-based intervention (Wantland, Portillo, Holzemer, Slaughter, \& McGhee, 2004). In another meta-analysis of 85 internet-based studies, Webb and colleagues (2010) found that the overall effect size of the interventions was small but significant $(d+=0.16)$, but that when the intervention was developed using a theoretical framework, the effect size was more than twice as large $(d+=0.33)$. These results, taken 
together suggest that computer-based interventions have an overall positive effect on health behaviors. However, given the variability in effect size reported by Wantland et al. (2004), it is important to determine the aspects of computer-based interventions that increase employees' exposure, participation, and success.

The dose-response relationship between increased participation in face-to-face HPPs and improved outcomes has been previously outlined (Serxner et al., 2003). To better understand the relationship between computer-based programs and participation, researchers reviewed engagement in The Prevention Plan across a sample of 7804 employees (Loeppke, Edington, Bender, \& Reynolds, 2013). Participants were stratified into three different engagement levels, with the first group only completing a HRA, the second group also completing at least one virtual or social challenge in the program, and the third group consisting of participants who took advantage of live coaching. Results showed that as participants increased their engagement in the program, there was a significant reduction in reported risk factors. The authors also documented a dose-response relationship between the number of times participants logged on to the program website and a reduction in risk factors (Loeppke et al., 2013). These results mirror findings of another meta-analysis that reported increased usage of a program's website was associated with positive weight change, suggesting that exposure to, and engagement in the webbased components of an intervention are critical to success (Eisen, Allen, Bollash, \& Pescatello, 2008; Neve, Morgan, Jones, \& Collins, 2010).

If effectiveness of computer-based interventions is directly related to the degree to which participants are exposed to and interact with these components, it is important then to identify the factors that promote exposure and participation with these interventions. One review of webbased interventions ( $n=64$ studies) found that peer or counselor support, in the form of phone 
calls or e-mails had a positive effect on the number of log-ins reported by participants (Brouwer et al., 2011). The authors also note that consistent updates to the website, as opposed to static content, were also positively related to the exposure that participants had to the online intervention components. Additional investigation into the characteristics of web-based interventions that influence exposure and effectiveness found that using automated tailored feedback $(d+=0.18)$, and connecting participants to an online advisor to whom they could ask advice $(d+=0.29)$ were effective ways to improve interventions (Webb et al., 2010). The authors also found that using text messages $(d+=0.81)$ and telephone supplementation $(d+=$ 0.35) of the online content had considerable impact on participant outcomes.

The impact of incentives on health promotion programs. One of the issues that has been raised in the development of HPPs is how to use incentives in a way that encourage participation and engagement in interventions, while also balancing ROI (Chapman, 2006). Ryan and colleagues (2008) also emphasize the fact that incentives may also undermine intrinsic motivation to do a certain behavior, since the individual is engaging in the behavior for an external reward as opposed to developing autonomous motivation to become healthier. With these factors in mind, it is important to get a better understanding of what incentives are traditionally implemented, whether or not they impact participation in HPPs, and the mechanisms behind how incentives motivate employees.

In a review of the literature that looked specifically at the relationship between incentives and health behaviors, Sutherland and colleagues (2008) identified two types of incentives; direct incentives (i.e., cash, gifts, or contributions to a health savings account), and indirect incentives (i.e., reductions in premiums, credit towards products and services). The authors reported that the most common incentives were cash, lotteries, and providing free food for participants. In 
another review, which looked at 47 articles, the authors found that coupons for free or reducedprice goods, cash incentives, gifts, and lotteries were used (Kane, Johnson, Town, \& Butler, 2004). In five of the seven studies that included cost-effectiveness assessments related to the use of incentives, the group that was incentivized was reported as more cost-effective than their nonincentivized counterparts. The authors also reported several studies that used negative reinforcement as an incentive for employees to engage in preventive behavior. The use of punishment was also identified as a potentially effective method of encouraging short-term participation by Sutherland and colleagues (2008), although they note that while individuals are often more attuned to negative consequences, punishment comes with undesirable side-effects (e.g., resentment of the employer, perception that the individual lacks autonomy related to their health behaviors).

When looking at ways to increase participation rates in HPPs, understanding the barriers that may get in the way, and how incentives might help employees overcome these barriers. In a survey that asked employees to identify their perceived barriers to participating, the most common responses were being too tired, not having interest in the programming that was offered, not having time before/during/after the work day, and not wanting to do it with coworkers (Kruger, Yore, Bauer, \& Kohl, 2007). When asked about incentives that might encourage them to participate despite these barriers, the most common responses were having the program scheduled at a convenient time $(73.2 \%$ of respondents), having the program at a convenient location (72.8\%), and getting paid time off to attend the program $(69.6 \%)$. These results suggest that although monetary incentives are most often utilized, that paid time off and scheduling programs at convenient times and locations may also encourage increased participation. 
Although incentivizing participation has been shown to be effective in increasing participation in short-term interventions, the mechanisms underlying how they work are not particularly well understood (Kane et al., 2004). Some authors suggest that incentives help to raise awareness and direct attention towards behaviors and outcomes they might otherwise ignore (e.g., the costs of their medical care and their behaviors are connected to medical cost; O’Donnell, 2010). It may be possible that incentives reinforce behavior in a more Skinnerian, direct way (Kane et al., 2004). More specifically, many unhealthy behaviors are done for the instant gratification and delayed costs associated with the behavior, while health behaviors often ask individuals to ignore the immediate costs and instead focus on the delayed benefits (Volpp, Asch, Galvin, \& Loewenstein, 2011). It has also been suggested that how the incentive is framed (e.g., as a bonus, as part of a larger paycheck, etc.) may also impact the effect it has on behavior (Sutherland et al., 2008).

Most of the reviewed literature has found mixed results related to incentives, reporting an increase in participation rates early on, with these effects diminishing over time, and with the possibility of negative long-term effects on behavioral maintenance (Kane et al., 2004; Rothstein \& Harrell, 2009). Consistent with SDT, it may be that people are motivated by the instant gratification of incentives and rewards, which act as external regulators, increasing extrinsic motivation while doing nothing to foster a sense of autonomy for the targeted behavior (Ryan et al., 2008). This could explain why much of the literature that reviews longitudinal outcomes related to incentivizing behavior reports a decrease in impact of incentives over time (Volpp, John, Troxel, Norton, Fassbender, \& Loewenstein, 2008). Furthermore, some researchers have moved away from a singular approach to both adoption and maintenance of behaviors, instead choosing to look at each process more distinctly (Schwarzer et al., 2008). It may be that 
incentives help individuals balance the pros and cons of initiating a behavior in favor of the healthful choice, but that a more targeted approach to developing autonomy and competence in the maintenance phase of a behavior is necessary. Until researchers have a clearer idea of the mechanisms of action related to incentivizing behavior, and without knowing the long-term impact of incentives, it is difficult to predict whether or not they facilitate sustainable health behavior change.

\section{Conclusions}

The literature evaluating HPPs provides some important insights regarding both the financial and clinical outcomes associated with worksite-based wellness programs. Using an array of methodologies, researchers have established a clear relationship between risk factors and healthcare costs, absenteeism, and reduced productivity. More specifically, obesity, stress, and having multiple risk factors are associated with increased healthcare costs (Aldana, 2001). Increased health risks may also cause as much as a $13 \%$ increase in absenteeism and has may account for up to $25 \%$ of overall healthcare cost (Anderson, Whitmer, Goetzel, Ozminkowski, Wasserman, \& Serxner, 2000; Edington \& Schultz, 2008). The relationship between HPPs and their impact on behavior and health risk reduction is well documented as well, with research reporting a consistently positive relationship between HPPs and health outcomes (Hutchinson \& Wilson, 2011). However, there remains a lack of longitudinal studies of HPPs, with the relationship between programs' impact on health risks and the manifestation of long-term ailments and disease still unclear. There is also a distinct lack of theory in much of the literature, making it difficult to understand the mechanisms that facilitate a HPPs impact, and to support the development and implementation of effective HPPs in the future. Regardless, there are still a 
number of important conclusions that emerged from examining literature on health behavior theories and HPPs.

There have been a number of programs, particularly for large companies (e.g., Johnson \& Johnson, Chrysler, PepsiCo.) that included multiple interventions geared towards influencing a constellation of behaviors. There is evidence to support the idea that programs that aim to affect a specific behavior are more effective than those that attempt to change multiple behaviors at once (Hutchinson \& Wilson, 2011). Drawing from the SEM of health promotion, it is clear that programs that address multiple levels of influence have a greater chance of positively influencing behavior. Particularly for organizations with limited resources, addressing organizational-level change, and adapting the environment that employees work in may provide greater return on investment (Stokols, 1996). It also seems clear that a "one-size-fits-all” model of developing interventions may not be as effective, and that tailoring the techniques to the health risk may facilitate improved outcomes (e.g., educational interventions targeting cholesterol reduction, with motivation enhancement techniques used for weight loss; Hutchinson \& Wilson, 2011).

By developing campaigns that are nested within a broader wellness program, it may be possible to tailor interventions to specific health risks, while still addressing multiple health risks across a given year. This approach was used with success by the WellSteps program, which also delineated each campaign into discrete weekly tasks to help participants stay oriented towards their next immediate step (LeCheminant \& Merrill, 2012). Building off of PMT, SCT, and SDT, which identify the self-efficacy/competence construct as integral in successful behavior change, developing weekly tasks throughout a campaign may simplify the change process and focus participants on small achievements, allowing them to build a sense of competence early in the program. Additionally, by prompting participants to recognize their small successes and how 
these successes positively impact their health, they may be more likely to develop a sense of competence, which in turn may help them as they shift from adoption of behaviors to maintenance (Floyd et al., 2000).

Motivation enhancement strategies, found in one review to be most effective in promoting PA behaviors, were defined by Sussman and colleagues (2000) as techniques that looked to develop competence in participants as well as help them find personal meaning in their intended change (Hutchinson \& Merrill, 2012). In a SDT framework, integrating a sense of meaning about one's behavior change into a broader worldview may help employees shift further towards intrinsic motivation to engage in health behaviors. To highlight the importance of autonomy in making successful behavior change, even when competence was not significantly different between two groups in a RCT, feelings of autonomy (e.g., control over one's program and choice related to whether or not to participate) were significantly associated with increased health behaviors (Fortier et al., 2007). In practice, this may look like providing employees with the opportunity to help design and implement interventions at their worksites, which has been shown to increase the effectiveness of HPPs (Conn et al., 2009; LeCheminant \& Merill, 2012; Sorensen et al., 1999). In addition to developing opportunities for employees to develop feelings of competence and autonomy, there are some practical recommendations to be taken from the HPP literature.

Strong evidence for a dose-response relationship between HPP participation and effectiveness has been established. Participants who complete HRAs yearly were found to have reduced health risks and healthcare costs when compared to those who completed them less frequently (Serxner et al., 2003). In one program, increased engagement in wellness programming was also related to improved clinical outcomes, with participants who participated 
in live coaching or virtual programming experiencing greater positive benefits than participants who only completed an HRA (Loeppke et al., 2013). Keeping participants engaged may also be a matter of keeping their attention, with programs that had at least one weekly contact demonstrating increased effectiveness (Rongen et al., 2013). Additional research, looking specifically at web-based interventions also found that participants who logged on more frequently were more likely to lose weight (Morgan et al., 2011). In a review of computer-based interventions, increased engagement was facilitated by follow-up text messages and phone calls, as well as connecting participants with a health professional online (Webb et al., 2010).

With all of the research done evaluating HPPs, the fact still remains that promoting health behaviors remains a complicated task. For nutrition behaviors alone, employees need to make a number of decisions each day in a variety of settings, and their thoughts and actions are influenced by a complex set of factors (Sorensen et al., 2004). In addition to the complexity of changing behavior, many HPPs seem to influence employees' intention to adopt healthy habits, without bridging the gap between intention and behavior. Drawing from PMT, it may be that the immediate gratification of unhealthy behaviors may manifest as hefty response costs when weighed against the delayed benefits, and often low perceived vulnerability, of choosing a healthy alternative (Norman et al., 2005).

While some interventions attempt to increase participants' knowledge of the severity of developing health risks, and potentially tip the balance towards choosing healthy behaviors, this may be an unsustainable method of motivating health-related changes. Participants may perceive a lack of autonomy in these situations, undermining their intrinsic motivation and providing them with only external motives for changing behavior. Other programs have attempted to use incentives to help increase the appeal of engaging in healthy behaviors when 
weighed against their unhealthy counterparts. Research into the use of incentives has found that participants may utilize HPPs more effectively when incentivized, providing for better costeffectiveness (Kane et al., 2004). However, there is a lack of research investigating the longterm effects of using incentives to motivate health behavior, with some researches suggesting that incentives may undermine intrinsic motivation as well as long-term behavior maintenance. Moving forward, it may be useful for researchers to begin approaching adoption and maintenance of health behaviors from a different angle, recognizing that getting employees started on the path to wellness may require different techniques than helping them stay there.

While the current review of the literature has established a number of "best practices" that interventionists can incorporate into wellness programming, there are also a number of areas where future research can be directed. First, the use of theory in developing and evaluating HPPs is still lacking, and our understanding of how to facilitate sustainable behavior change is unclear. While technology has been highlighted in a number of the HPPs reviewed here, there are still a number of aspects related to technology use in HPPs that are not understood. Research looking at how to facilitate increased participation, including the use of novel technologies (e.g., FitBit and other accelerometer-style technologies), rather than only web and e-mail based interventions may prove useful. Additionally, researchers may need to get a better understanding of the reach of technological interventions, in an effort to understand whether or not these interventions serve particular populations more effectively than others. Lastly, HPPs seem to lack a comprehensive approach to individual behavior change, despite evidence that suggests that interventions that address multiple levels of the social ecological model may be more effective. Future research efforts may need to focus on how to more effectively address environmental and organizational determinants of behavior in a way that isn't resource intensive. 


\section{References}

Aldana, S. G. (2001). Financial impact of health promotion programs: A comprehensive review of the literature. American Journal of Health Promotion, 15(5), 296-320.

Anderson, D. R., Whitmer, R. W., Goetzel, R. Z., Ozminkowski, R. J., Wasserman, J., \& Serxner, S. (2000). The relationship between modifiable health risks and group-level health care expenditures. American Journal of Health Promotion, 15(1), 45-52.

Baicker, K., Cutler, D., \& Song, Z. (2010). Workplace wellness programs can generate savings. Health Affairs 29(2), 304-311.

Bandura, A. (1991). Social cognitive theory of self-regulation. Organizational Behavior and Human Decision Processes, 50, 248-287.

Bedell, W., Kaszkin-Bettag, M. (2010). Coherence and health care cost - RCA actuarial study: a cost-effectiveness cohort study. Alternative Therapies, 16(4), 26-31.

Berry, L.L., Mirabito, A. M., \& Baun, W. B. (2010). What's the hard return on employee wellness programs? Harvard Business Review, 88(12), 104-112.

Blair, S. N., Piserchia, P. V., Wilbur, C. S., \& Crowder, J. H. (1986). A public health intervention model for work-site health promotion. Journal of the American Medical Association, 255, 921-926.

Bly, J., Jones, R., \& Richardson, J. (1986). Impact of worksite health promotion on health care costs and utilization: evaluation of Johnson \& Johnson's Live for Life program. The Journal of the American Medical Association, 256(23), 3235-3240.

Bui, L., Mullan, B., \& McCaffery, K. (2013). Protection motivation theory and physical activity in the general population: a systematic literature review. Psychology, Health \& Medicine. doi: $10.1080 / 13548506.2012 .749354$ 
Brouwer, W., Kroeze, W., Crutzen, R., de Nooijer, J., de Vries, N. K., Brug, J., \& Oenema, A. (2011). Which intervention characteristics are related to more exposure to internet-delivered healthy lifestyle promotion interventions? A systematic review. Journal of Medical Internet Research, 13(1), e2.

Carpenter, C. J. (2010). A meta-analysis of the effectiveness of health belief model variables in predicting behavior. Health Communications, 25, 661-669.

Chandola, T., Brunner, E., \& Marmot, M. (2006). Chronic stress at work and the metabolic syndrome: prospective study. British Medical Journal, 332(7540), 521-525.

Chapman, L. S. (2003). Meta-evaluation of worksite health promotion economic return studies. American Journal of Health Promotion, 17(3), 1-10.

Chapman, L. S. (2005). Meta-evaluation of worksite health promotion economic return studies: 2005 update. American Journal of Health Promotion, 19(6), 1-10.

Chapman, L. (2006). Employee participation in workplace health promotion and wellness programs: how important are incentives, and which work best? North Carolina Medical Journal, 67(6), 431-432.

Chapman, L. (2012). Meta-evaluation of worksite health promotion economic return studies: 2012 update. American Journal of Health Promotion, 26(4), TAHP1-TAHP12.

Conn, V. S., Hafdahl, A. R., Cooper, P. S., Brown, L. M., \& Lusk, S. L. (2009). Meta-analysis of workplace physical activity interventions. American Journal of Preventive Medicine, 37(4), $330-339$.

Cox, D. N., Koster, A., \& Russell, C. G. (2004). Predicting intentions to consume functional foods and supplements to offset memory loss using an adaptation of protection motivation theory. Appetite, 43(1), 55-64. 
De Bourdeauhuij, I., Stevens, V., Vandelanotte, C., \& Brug, J. (2007). Evaluation of an interactive computer-tailored nutrition intervention in a real-life setting. Annals of Behavioral Medicine, 33(1), 39-48.

Edington, D. W., \& Schultz, A. B. (2008). The total value of health: a review of literature. International Journal of Workplace Health Management, 1(1), 8-19.

Eisen, K. P., Allen, G. J., Bollash, M., \& Pescatello, L. S. (2008). Stress management in the workplace: A comparison of a computer-based and an in-person stress-management intervention. Computers in Human Behavior, 24, 486-496.

Erfurt, J. C., Foote, A., \& Heirich, M. A. (1991). Worksite wellness programs: incremental comparison of screening and referral alone, health education, follow-up counseling, and plant organization. American Journal of Health Promotion, 5(6), 438-448.

Floyd, D. L., Prentice-Dunn, S., \& Rogers, R. W. (2000). A meta-analysis of research on protection motivation theory. Journal of Applied Social Psychology, 30(2), 407-429.

Fortier, M. S., Sweet, S. N., O’Sullivan, T. L., \& Williams, G. C. (2007). A self-determination process model of physical activity adoption in the context of a randomized controlled trial. Psychology of Sport and Exercise, 8, 741-757.

Fries, J. F., Harrington, H., Edwards, R., Kent, L. A., \& Richardson, N. (1994). Randomized controlled trial of cost reductions from a health education program: The California Public Employees' Retirement System (PERS) Study. American Journal of Health Promotion, 8(3), 216-223.

Golaszewski, T. (2001). Shining lights: studies that have most influenced the understanding of health promotion's financial impact. American Journal of Health Promotion, 15(5), 332 340. 
Hagger, M. S., Chatzisarantis, N. L. D., \& Biddle, S. J. H. (2002). A meta-analytic review of the theories of reasoned action and planned behavior in physical activity: predictive validity and the contribution of additional variables. Journal of Sport \& Psychology, 24, 3-32.

Harvey, M. R., Whitmer, R. W., Hilyer, J. C., \& Brown, K. C. (1993). The impact of a comprehensive medical benefit cost management program for the city of Birmingham: results at five years. American Journal of Health Promotion, 7(4), 296-303.

Henke, R. M., Goetzel, R. Z., McHugh, J., \& Isaac, F. (2011). Recent experience in health promotion at Johnson \& Johnson: lower health spending strong return on investment. Health Affairs, 30(3), 490-499.

Hochart, C., \& Lang, M. (2011). Impact of a comprehensive worksite wellness program on health risk, utilization, and health care costs. Population Health Management, 14(3), 111 116.

Hutchinson, A. D., \& Wilson, C. (2011). Improving nutrition and physical activity in the workplaces: a meta-analysis of intervention studies. Health Promotion International, 27(2), 238-249.

Kane, R. L., Johnson, P. E., Town, R. J., \& Butler, M. (2004). A structured review of the effect of economic incentives on consumers' preventive behavior. American Journal of Preventive Medicine, 27(4), 327-352.

Kruger, J., Yore, M. M., Bauer, D. R., \& Kohl, H. W. (2007). Selected barriers and incentives for worksite health promotion services and policies. American Journal of Health Promotion, $21(5), 439-447$. 
LeCheminant, J. D., \& Merrill, R. M. (2012). Improved health behaviors persist over two years for employees in a worksite wellness program. Population Health Management, 15(2), 261266.

Liu, H., Harris, K. M., Weinberger, S., Serxner, S., Mattke, S., \& Exum, E. (2013). Effect of an employer-sponsored health and wellness program on medical cost and utilization. Population Health Management, 16(1), 1-6.

Linnan, L. A., Sorensen, G., Colditz, G., Klar, N., \& Emmons, K. M. (2001). Using theory to understand the multiple determinants of low participation in worksite health promotion programs. Health Education \& Behavior, 28(5), 591-607.

Loeppke, R., Edington, D., Bender, J., \& Reynolds, A. (2013). The association of technology in a workplace wellness program with health risk factor reduction. Journal of Occupational and Educational Medicine, 55(3), 259 - 264.

Milani, R. V., \& Lavie, C. J. (2009). Impact of worksite wellness intervention on cardiac risk factors and one-year health care costs. The American Journal of Cardiology, 104 1389-1392.

Morgan, P. J., Collins, C. E., Plotnikoff, R. C., Cook, A. T., Berthon, B., Mitchell, S., \& Callister, R. (2011). Efficacy of a workplace-based weight loss program for overweight male shift workers: the workplace POWER (Preventing Obesity Without Eating like a Rabbit) randomized controlled trial. Preventive Medicine 52(5), 317-325.

Morgan, P. J., Collins, C. E., Plotnikoff, R. C., Cook, A. T., Berthon, B., Mitchell, S., \& Callister, R. (2012). The impact of a workplace-based weight loss program on work-related outcomes in overweight male shift workers. Journal of Occupational and Environmental Medicine, 54(2), 122-127. 
Mhurchu, C. N., Aston, L. M., \& Jebb, S. A. (2010). Effects of worksite health promotion interventions on employee diets: a systematic review. BMC Public Health, 10(62), 1-7.

Naydeck, B. L., Pearson, J. A., Ozminkowski, R. J., Day, B. T., \& Goetzel, R. Z. (2008). The impact of the highmark employee wellness programs on 4-year healthcare costs. Journal of Occupational and Environmental Medicine, 50, 146-156.

Neve, M., Morgan, P. J., Jones, P. R., \& Collins, C. E. (2010). Effectiveness of web-based interventions in achieving weight loss and weight loss maintenance in overweight and obese adults: a systematic review with meta-analysis. Obesity Reviews, 11, 306-321.

Nicholson, S., Pauly, M. V., Polsky, D., Baase, C. M., Billotti, G. M., Ozminkowski, R. J., ... Sharda, C. E. (2005). How to present the business case for healthcare quality to employers. Applied Health Economics and Health Policy, 4(4), 209-218.

Noar, S. M., \& Zimmerman, R. S. (2005). Health behavior theory and cumulative knowledge regarding health behaviors: are we moving in the right direction? Health Education Research, 20(3), 275-290.

Norman, P., Boer, H., \& Seydel, E. R. (2005). Protection Motivation Theory. In: M. Conner and P. Norman (eds.), Predicting health behaviour: research and practice with social cognitive models (pp. 81 -126). Maidenhead: Open University Press.

Nyce, S., Grossmeier, J., Anderson, D. R., Terry, P. E., \& Kelley, B. (2012). Association between changes in health risk status and changes in future health care costs: a multiemployer study. Journal of Occupational and Environmental Medicine, 54(11), 13641373.

O’Donnell, M. P. (2010). Editor's notes. American Journal of Health Promotion, 24(4), iv-vi. 
Park, O., Hoover, L., Dodd, T., Huffman, L., \& Feng, D. (2010). The use of the modified protection motivation theory to explore adult consumers' functional foods consumption behavior. Unpublished manuscript, Department of Nutrition, Hospitality, \& Retailing, Texas Tech University, Texas United States of America.

Pelletier, K. R. (2011). A review and analysis of the clinical and cost-effectiveness studies of comprehensive health promotion and disease management programs at the worksite. Journal of Occupational and Educational Medicine, 53(11), 1310-1331.

Pelletier, L.G., Dion, S. C., Slovinec-D’Angelo, M., \& Reid, R. (2004). Why do you regulate what you eat? Relationships between forms of regulation, eating behaviors, sustained dietary change, and psychological adjustment. Motivation and Emotion, 28(3), 245-277.

Phillips, J. F. (2009). Using an ounce of prevention: does it reduce health care expenditures and reap pounds of profits? A study of the financial impact of wellness and health risk screening programs. Journal of Health Care Finance, 36(2), 1-12.

Plotnikoff, R. C., \& Trinh, L. (2010). Protection motivation theory: is this a worthwhile theory for physical activity promotion? Exercise and Sport Science Reviews, 38(2), 91-98.

Richard, L., Potvin, L., Kishchuk, N., Prlic, H., \& Green, L. W. (1996). Assessment of the integration of the ecological approach in health promotion programs. American Journal of Health Promotion, 10(4), 318-328.

Robroek, S. J. W., Polinder, S., Bredt, F. J., \& Burdorf, A. (2012). Cost-effectiveness of a longterm internet-delivered worksite health promotion programme on physical activity and nutrition: a cluster randomized controlled trial. Health Education Research, 27(3), 399-410. Rogers, R. W. (1975). A protection motivation theory of fear appeals and attitude change. The Journal of Psychology, 91, 93-114. 
Rogers, R. W. (1983). Cognitive and physiological process in fear appeals and attitude change: a revised theory of protection motivation. In J.T. Cacioppo and R.E. Petty (eds) Social Psychophysiology: A Source Book. New York: Guilford Press, 153-176.

Rongen, A., Robroek, S.J.W., van Lenthe, F. J., \& Burdorf, A. (2013). Workplace health promotion: a meta-analysis of effectiveness. American Journal of Preventive Medicine, 44(4), 406-415.

Rothstein, M. A., \& Harrell, H. L. (2009). Health risk reduction programs in employer-sponsored health plans: part I - Efficacy. Journal of Occupational and Environmental Medicine, 51(8), 943-950.

Ryan, R. M., \& Deci, E. L. (2000). Self-determination theory and the facilitation of intrinsic motivation, social development, and well-being. American Psychologist, 55(1), 58-78.

Ryan, R. M., Patrick, H., Deci, E. L., \& Williams, G. C. (2008). Facilitating health behaviour change and its maintenance: interventions based on self-determination theory. The European Health Psychologist, 10, 2-5.

Sallis, J. F., \& Owen, N. (2002). Ecological models of health behavior. Health Behavior and Health Education: Theory, Research, and Practice. K. Glanz, B. K. Rimer, \& F. MarcusLewis (Eds.). San Francisco, CA: Jossey-Bass.

Schwarzer, R. (2008). Modeling health behavior change: how to predict and modify the adoption and maintenance of health behaviors. Applied Psychology: An International Review, 57(1), 129.

Serxner, S. A., Gold, D. B., Grossmeier, J. J., \& Anderson, D. R. (2003). The relationship between health promotion program participation and medical costs: a dose response. Journal of Occupational and Environmental Medicine, 45, 1196-1200. 
Sorensen, G., Linnan, L., \& Hunt, M. K. (2004). Worksite-based research and initiatives to increase fruit and vegetable consumption. Preventive Medicine, 39, S94-S100.

Sorensen, G., Stoddard, A., Peterson, K., Cohen, N., Hunt, M. K., Stein, E., . . Lederman, R. (1999). Increasing fruit and vegetable consumption through worksites and families in the Treatwell 5-a-Day Study. American Journal of Public Health, 89(1), 54-60.

Stokols, D. (1992). Establishing and maintaining healthy environments. American Psychologist, 47(1), 6-22.

Stokols, D. (1996). Translating social ecological theory into guidelines for community health promotion. American Journal of Health Promotion, 10(4), 282-298

Stokols, D., Pelletier, K. R., \& Fielding, J. E. (1996). The ecology of work and health: research and policy directions for the promotion of employee health. Health Education \& Behavior, 23(2), 137-158.

Sussman, S., Sun, P., \& Dent, C. W. (2006). A meta-analysis of teen cigarette smoking cessation. Health Psychology, 25(5), 549-557.

Sutherland, K., Christianson, J. B., \& Leatherman, S. (2008). Impact of targeted financial incentives on personal health behavior: a review of the literature. Medical Care Research Review, 65(6), 36S-78S.

Verweij, L. M., Coffeng, J., van Mechelen, W., \& Proper, K. I. (2011). Meta-analyses of workplace physical activity and dietary behavior interventions on weight outcomes. Obesity Review, 12(6), 406-429.

Volpp, K. G., Asch, D. A., Galvin, R., \& Loewenstein, G. (2011). Redesigning employee health incentives - lessons from behavior economics. The New England Journal of Medicine, $365(5), 388-390$. 
Volpp, K. G., John, L. K, Troxel, A. B., Norton, L., Fassbender, J., \& Loewenstein, G. (2008). Financial incentive-based approaches for weight loss: a randomized trial. Journal of the American Medical Association, 300(22), 2631-2637.

Wantland, D. J., Portillo, C. J., Holzemer, W. L., Slaughter, R., \& McGhee, E. M. (2004). The effectiveness of web-based vs. non-web-based interventions: a meta-analysis of behavioral change outcomes. Journal of Medical Internet Research, 6(4), e40.

Webb, T. L., Joseph, J., Yardley, L., \& Michie, S. (2010). Using the internet to promote health behavior change: a systematic review and meta-analysis of the impact of theoretical basis, use of behavior change techniques, and mode of delivery on efficacy. Journal of Medical Internet Research, 12(1), 97-114.

Wolever, R. Q., Bobinet, K. J., McCabe, K., Mackenzie, E. R., Fekete, E., Kusnick, C. A., \& Baime, M. (2012). Effective and viable mind-body stress reduction in the workplace: a randomized controlled trial. Journal of Occupational Health Psychology, 17(2), 246-258. 